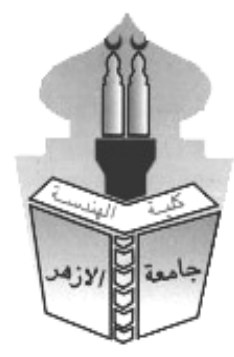

\title{
ECO CITY AND ITS ROLE IN ACHIEVING SUSTAINABLE INDUSTRIAL DEVELOPMENT. CASE STUDY ALEXANDRIA GOVERNORATE
}

\author{
Shaban Abu Khtwah* and Gamal Gomaa Helewa \\ AL-Azhar University,Faculty of Engeneering,Urban Planning Departement,Cairo, Egypy \\ *Corresponding Author E-mail: drshaban@azhar.edu.eg
}

\section{ABSTRACT}

As The vision of the economic axis and the sustainable development strategy of Egypt 2030 is that the Egyptian economy is a disciplined market economy characterized by stable macroeconomic conditions and able to achieve sustainable and sustainable growth that meets local demand and an effective player in the global economy.

There is no doubt that the industry is one of the fastest ways of development as it works to raise the national income. In Egypt, industry occupies the same importance as agriculture, which contributes about $28 \%$ of the national income. Egypt ranked second after the Republic of South Africa in terms of industrial development in the continent Africa 'However, most Arab countries, especially Egypt, find that the industry is facing difficult and difficult challenges. The most important of these is the inability to keep abreast of developments in the field of environmentally friendly industrial technology. It is well known that most of the Egyptian cities, On the urban environment and where the industry and the resulting pollutants play a major role in harming the environment with its various elements, which negatively affects the population and reduce the productivity of these activities, and this is one of the challenges of industrial development because of the negative repercussions on the Efforts directed attention to the development of industrial activities of various kinds, and this is what makes us think about and quickly switch to the green industry as one of the key solutions and ideal for it.

\section{KEYWORDS: Green Industry,Sustainable Development,Sustainable Industrial Development, Industrial Parks, Industrial Takaful)}

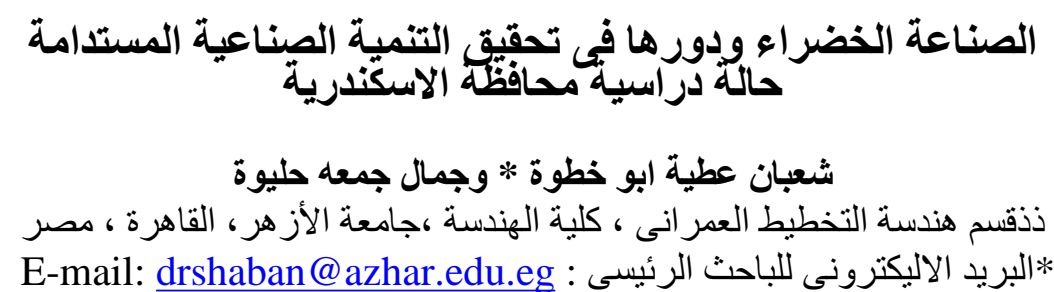




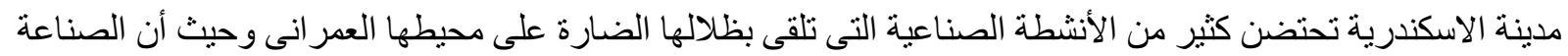

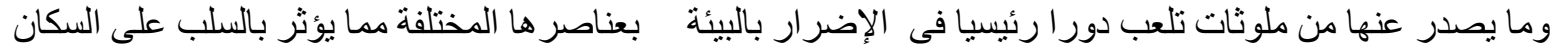

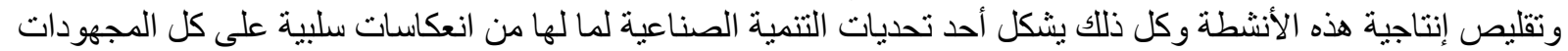

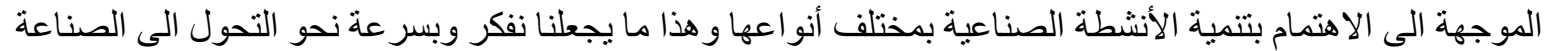

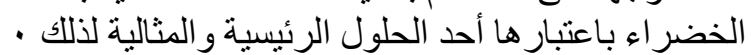

\section{الكلمات المفتاحية: الصناعة الخضراع، التنمية المستدامة ،التنمية الصناعية المستدامة،المتنزهات الصناعية ، التكافل

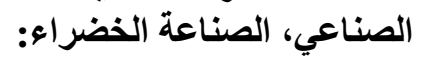

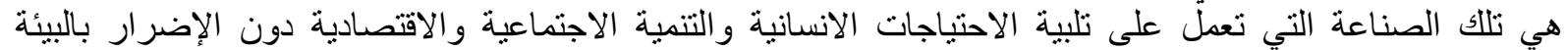

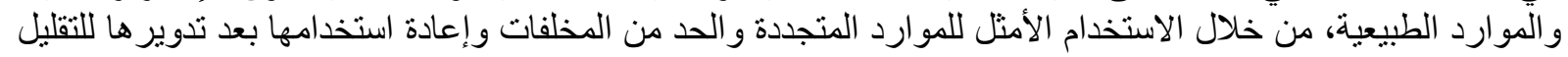

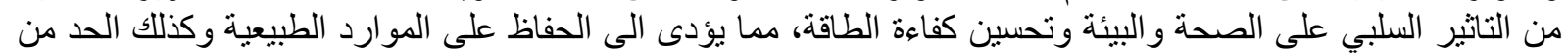

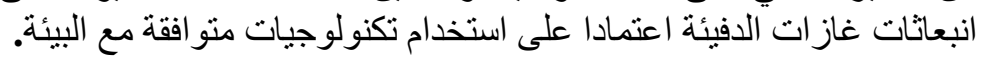

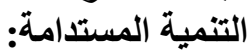

تعرف بأنها التنمية التي تلبي الإحتياجات الحالية دون المساومة على قدرة الأجيال المقبلة في تلبية حاجاتهم؛ فهى تنمية

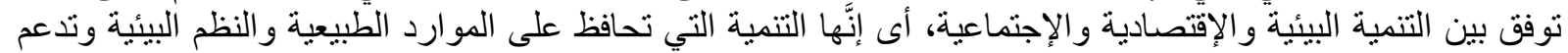

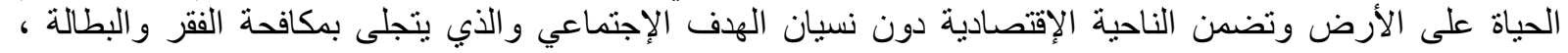

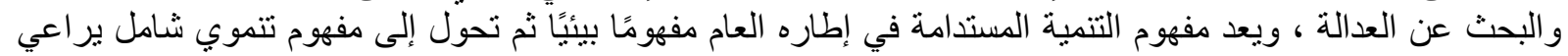

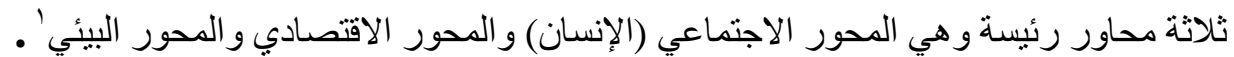

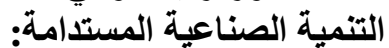

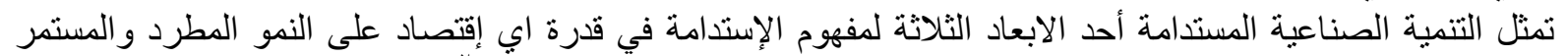

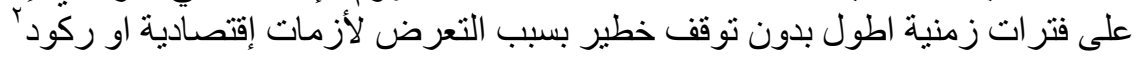

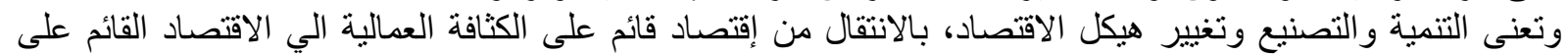

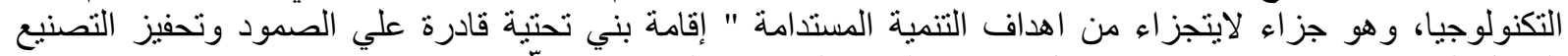

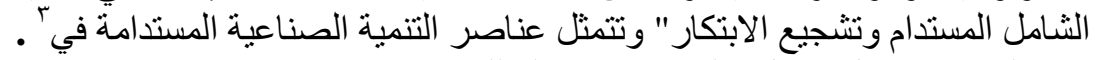

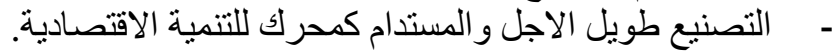

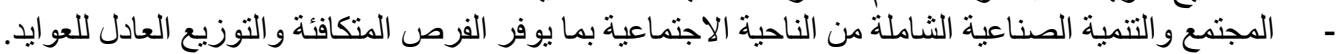

الاستدامة البيئية و التوازن بين الرخاء الناتج من الصناعة وبين الاستغلال المفرط للمواعة الكارد الطبيعية.

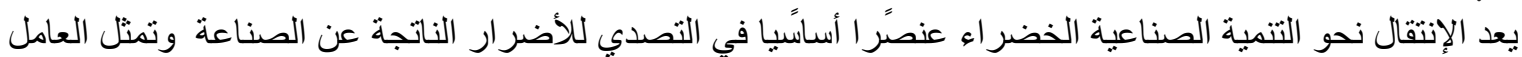

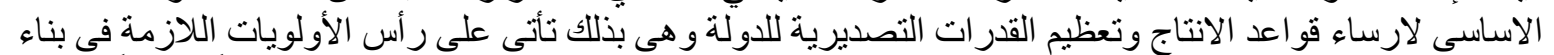

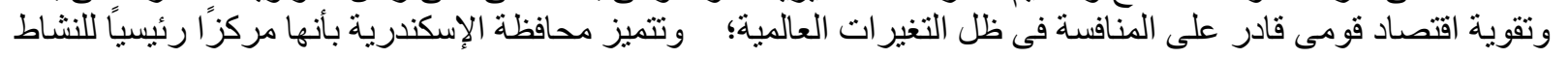

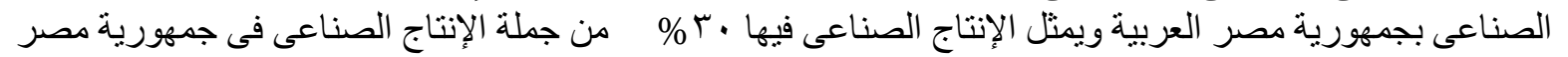

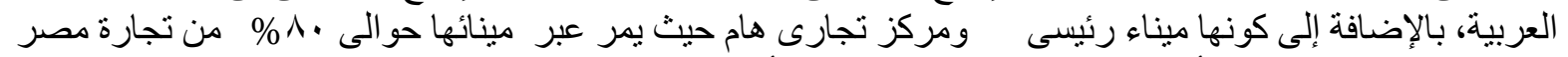

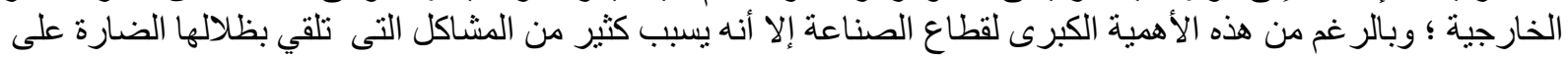

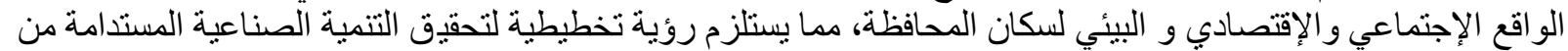

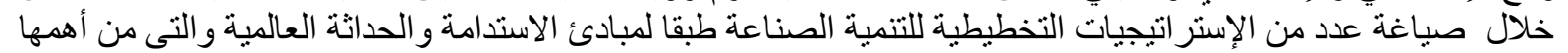

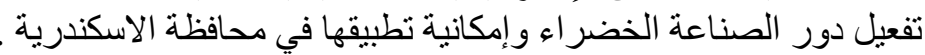

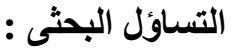

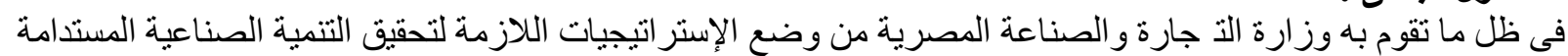

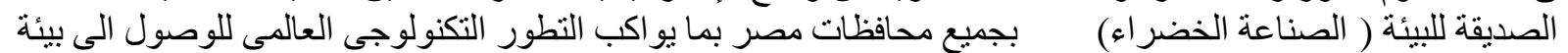

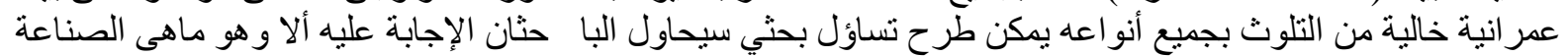

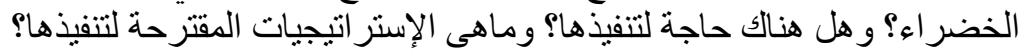

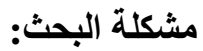

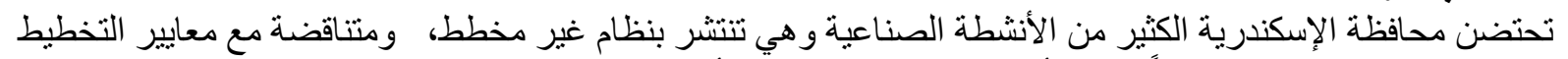

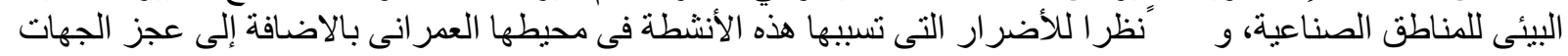

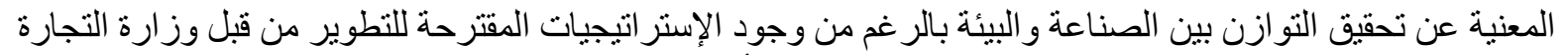

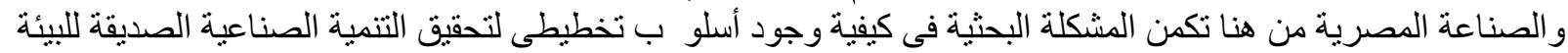
(الصناعة الخضر اء) بما يضمن تحقيق بيئة عمر انية خالية من التلوث في محافظة الاسكندرية. 
أهداف البحث:

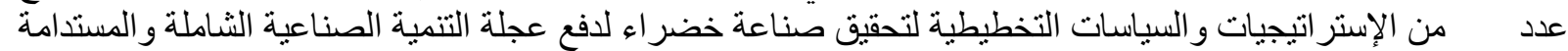
و الصديقة للبيئة فى ضوء الإنر تحقيق مبادئ ومعايير التخطيط البيئى للمناطق الصناعية خطية.

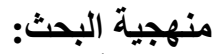

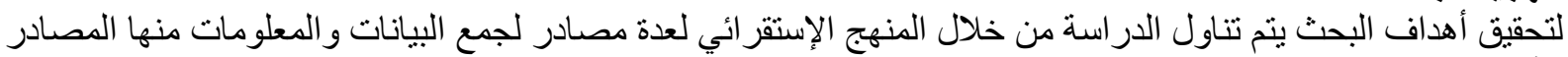

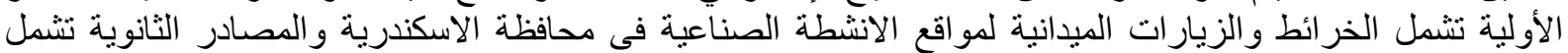

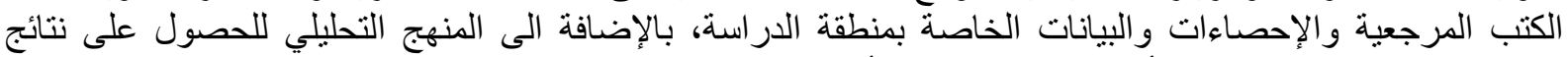

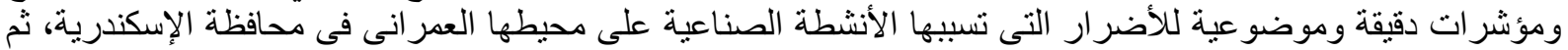

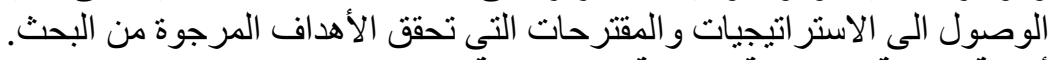

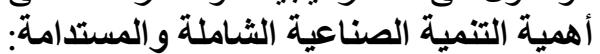

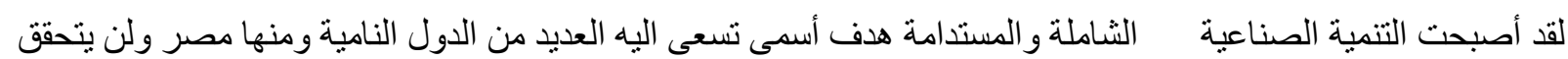

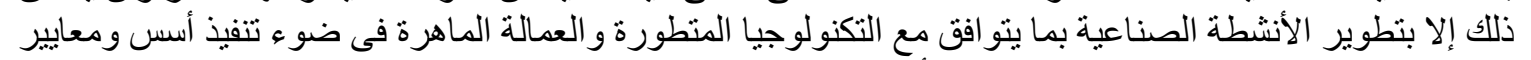

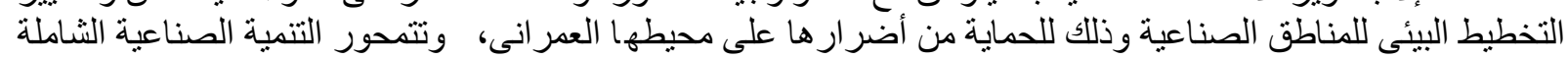

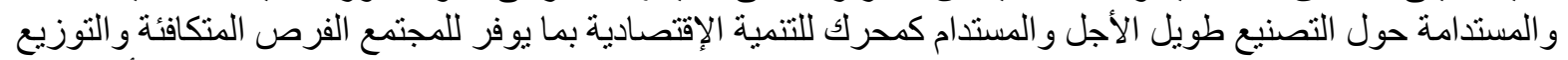

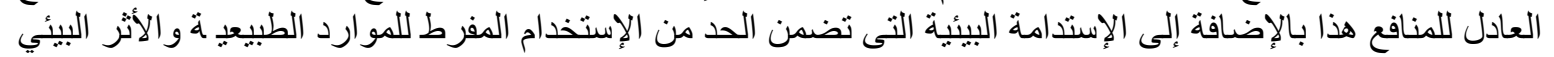

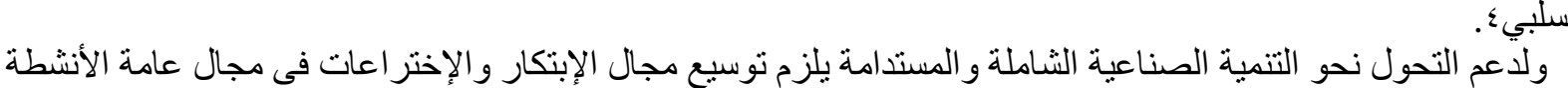

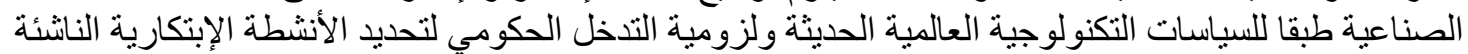

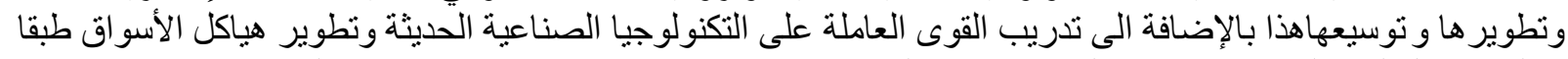

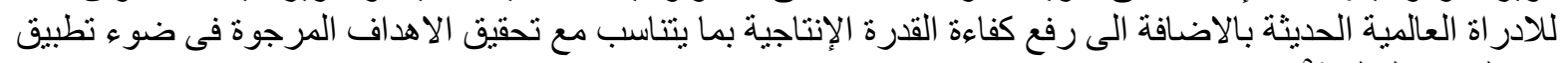
معايير الجودة العالمية.

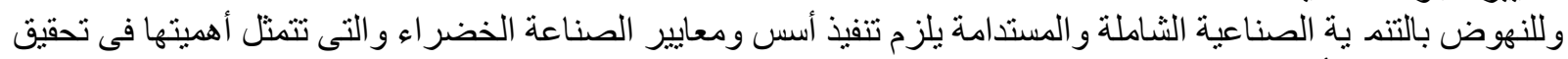

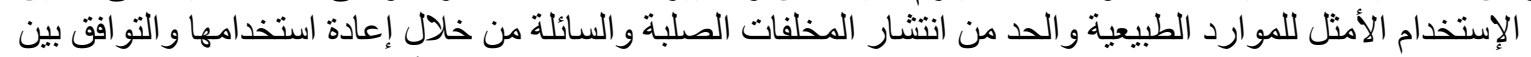

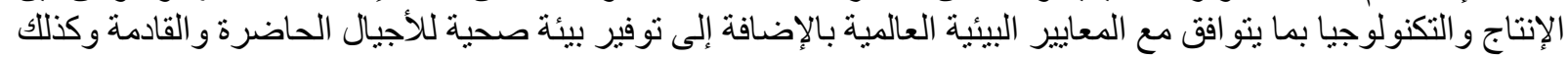

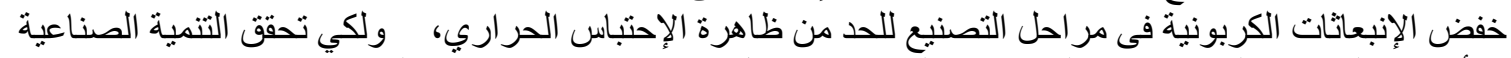

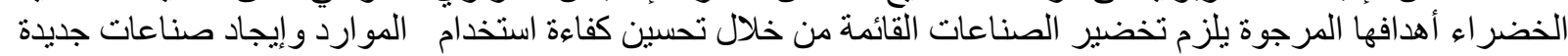

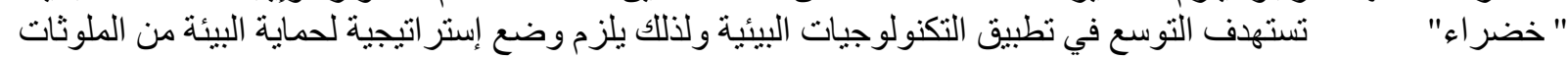

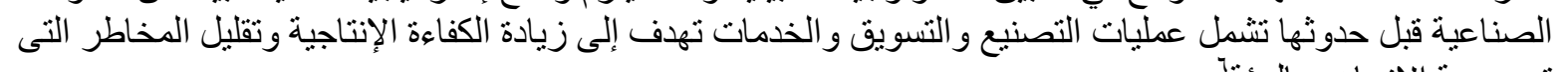

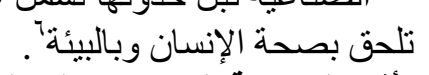

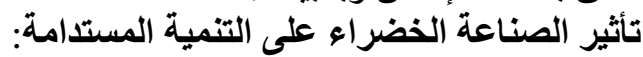

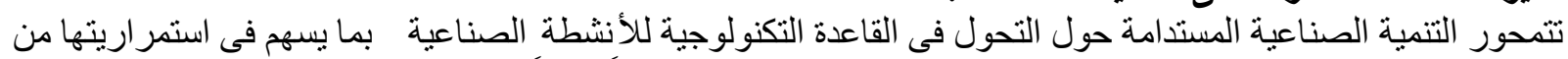

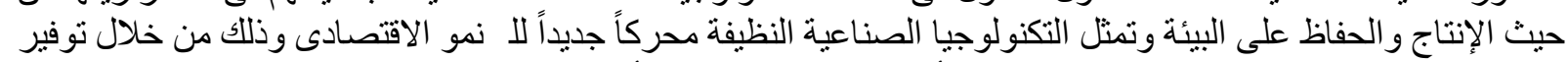

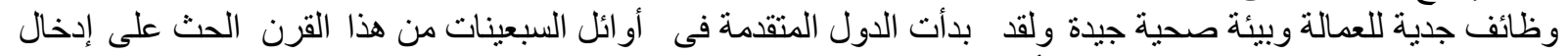

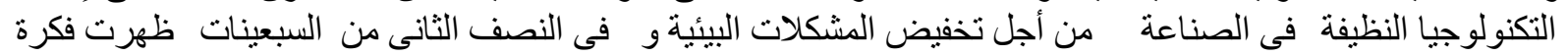

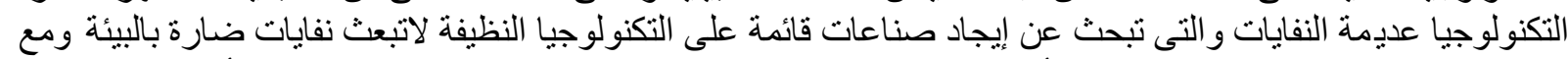

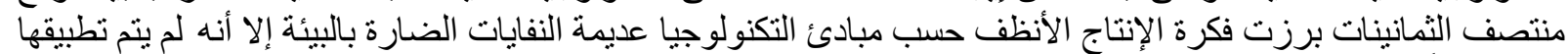

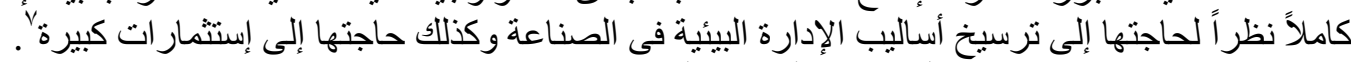

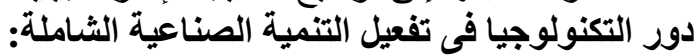

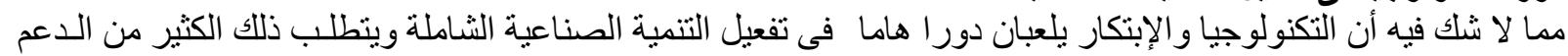

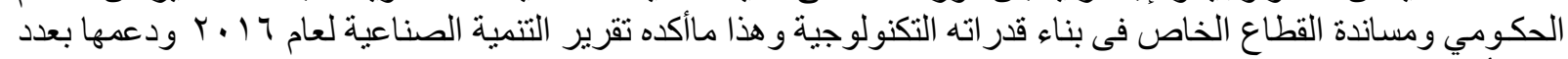

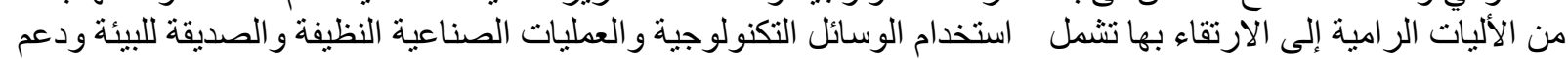

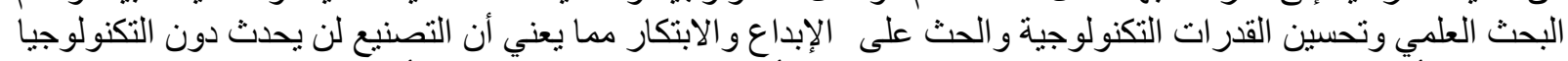

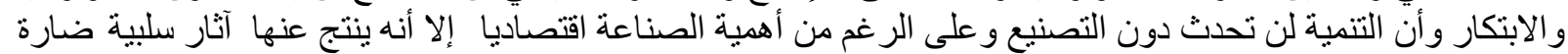

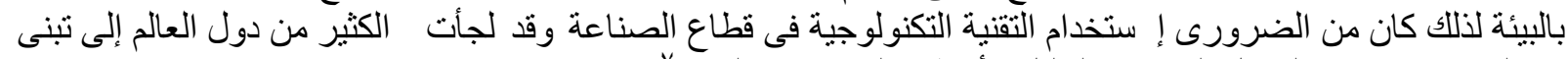

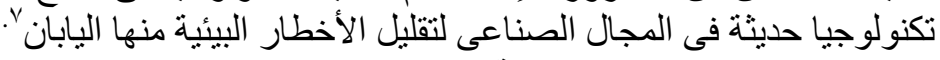

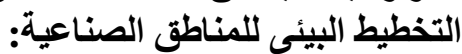

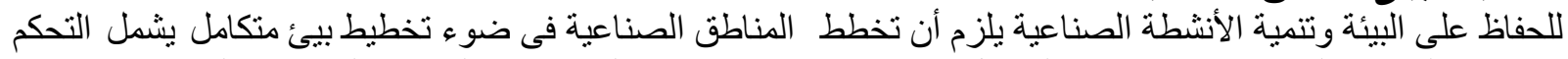
فى إدارة المو ارد البيئية بكفاءة ودر اسة العو امل الإجتماعية والإِ قتصادية لمخططات المناطق الصناعية لتحديد الاتجاهات 


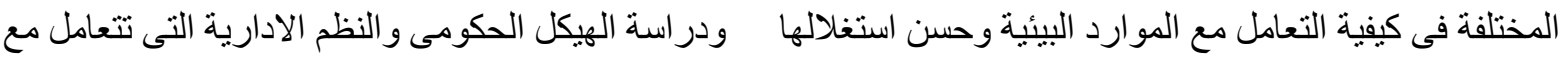

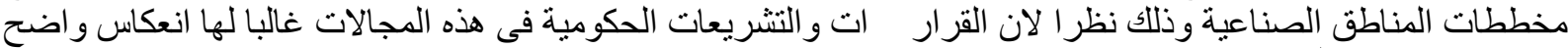

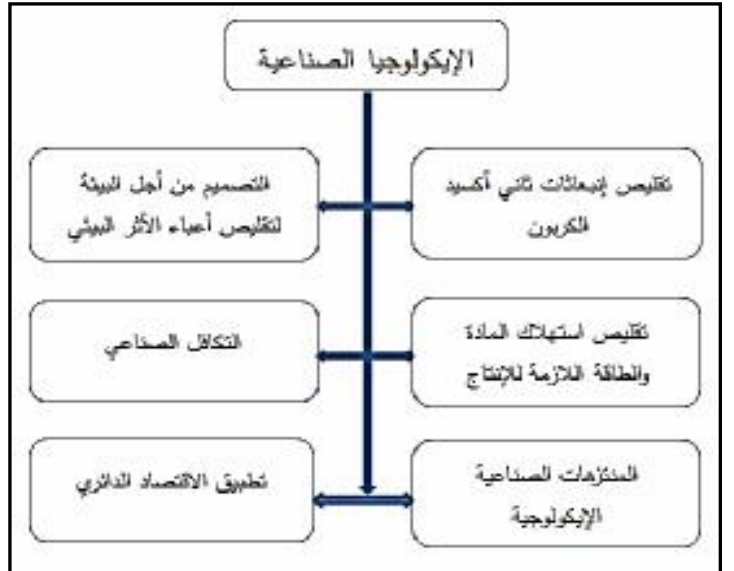

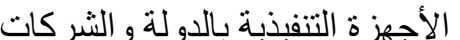
على القضايا البيئية.

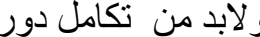

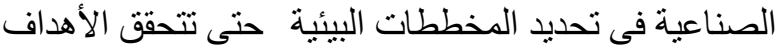

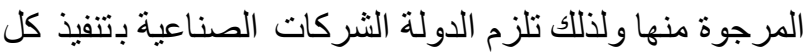

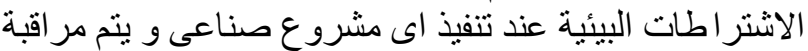

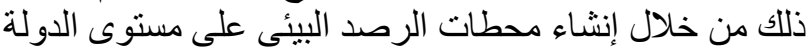

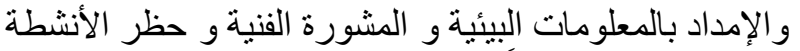

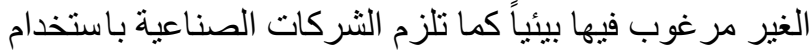

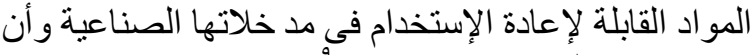

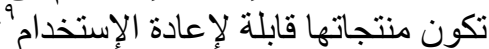
الإيكولوجيا الصناعية كأساس للتنمية المستدامة الإنة:

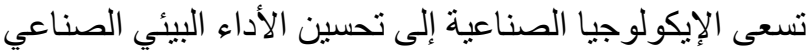

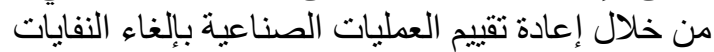

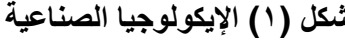

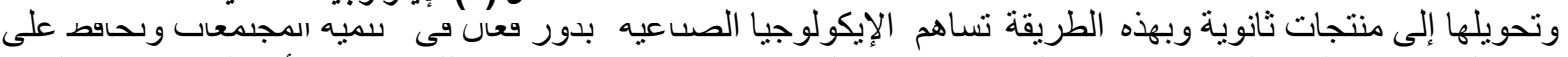

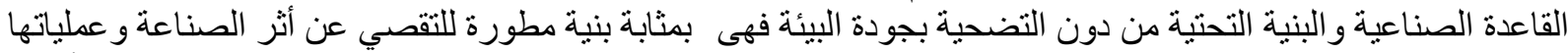

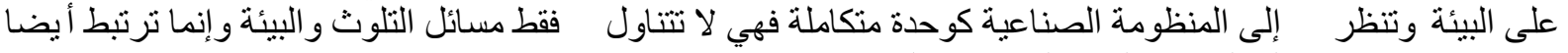

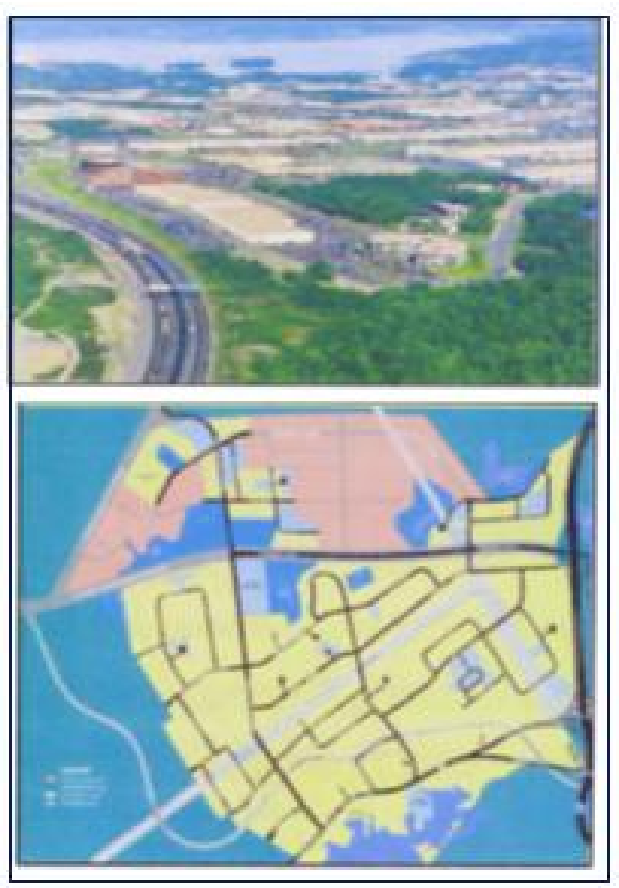

شكل (Y) مخطط المتنزه الصناعى بمنطقة برنسايد

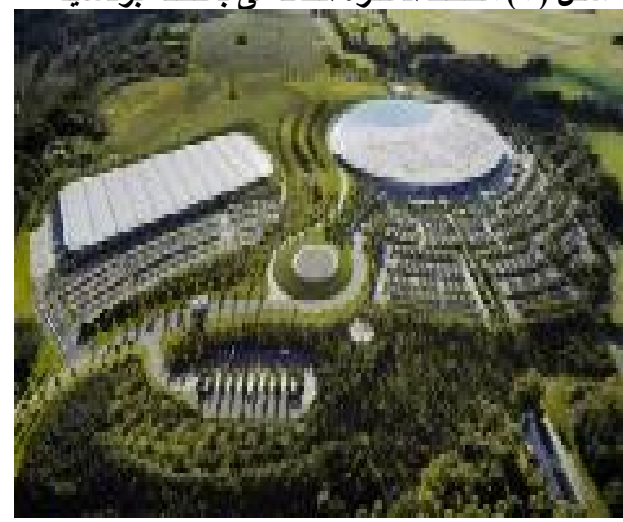
بالاقتصاد فى استهالك الطاقة و المادة الخام و بعمليات الانتاج ونموه و هي بذلك تجعل المنظومات الصناعية في تو افقية مع محيطها المجاور و الثنكل رقم (1 ) يبين ماتتضمنه الإيكولوجيا الصناعي". المتنز هات الصناعية

هى مجمو عة من المصانع و الوحدات الصناعية تعمل مع بعضها

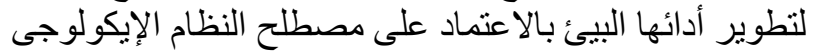

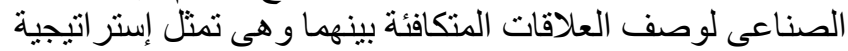

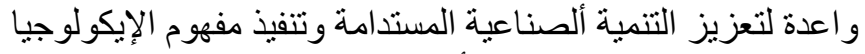

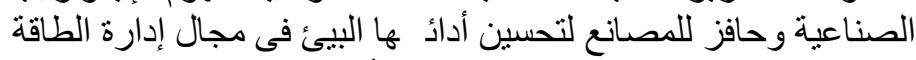

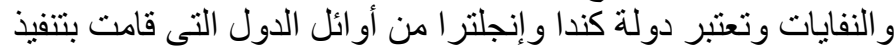
فكرة ألكتنز هات ألصناعية ففى كندا تم تنفيذ المتنزه الصنائل الصناعى بمنطقة

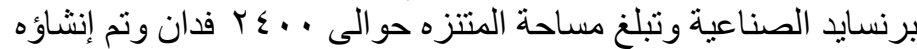

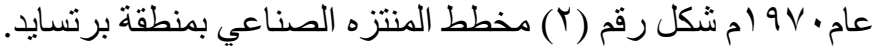

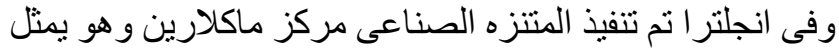

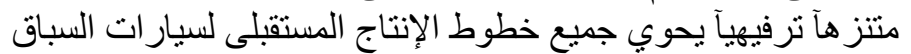

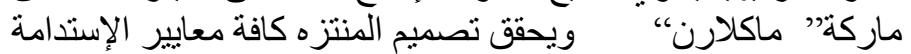

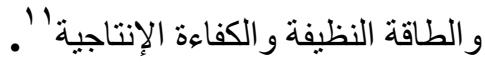

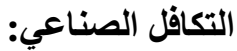

مفهوم يعني إستفادة الثركات من بعضها البعض حيث تصبح نفايات

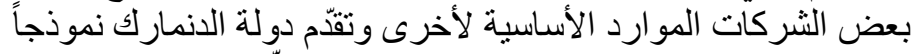

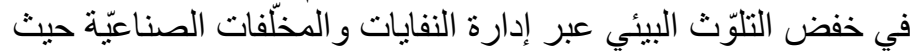

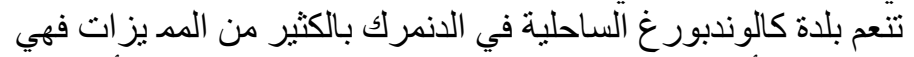

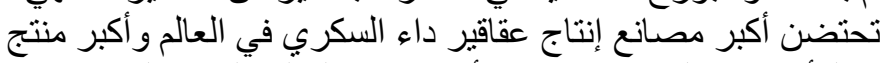

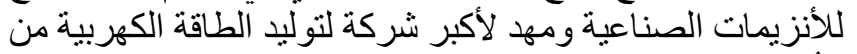

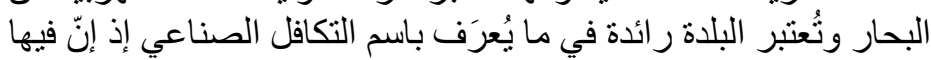

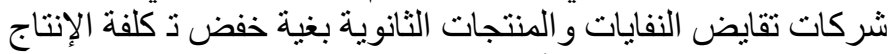

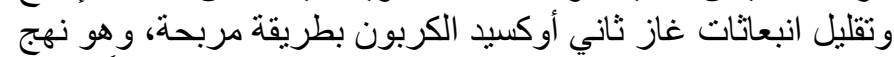

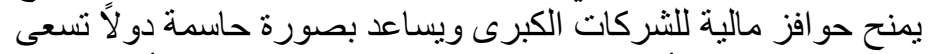

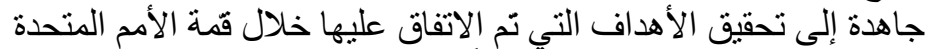
لتغبّر المناخ ، وكان نجاح البلدة سبياً في لفت أذظار العالم إليها، وزارها 
ممثلو أكثر من · ب شركة عالمية ورؤساء المجالس البلدية من · r دولة بما في ذلك مسؤولون من إقليم "قواندونغ" المزدهر

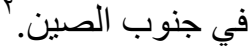

المنظور البيئي للتنمية العمرانية:

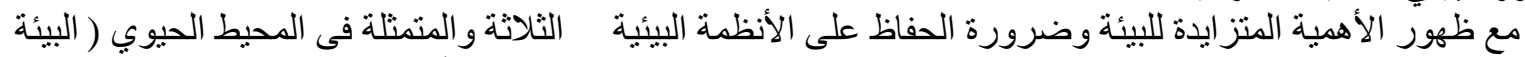

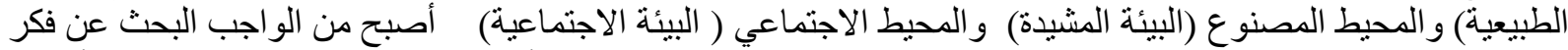

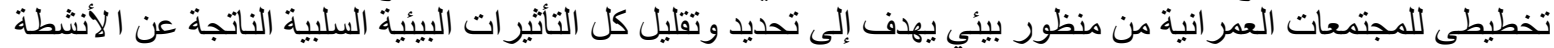

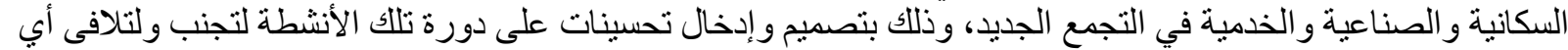

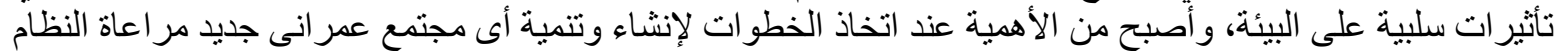

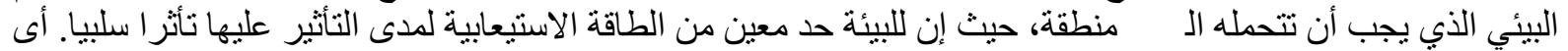

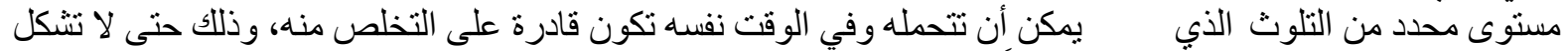

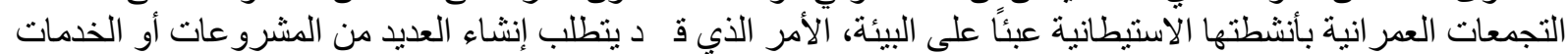

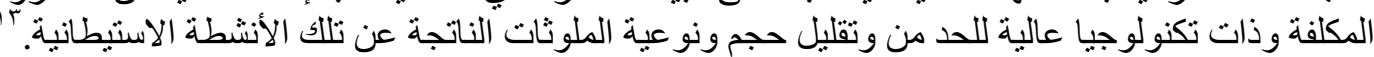

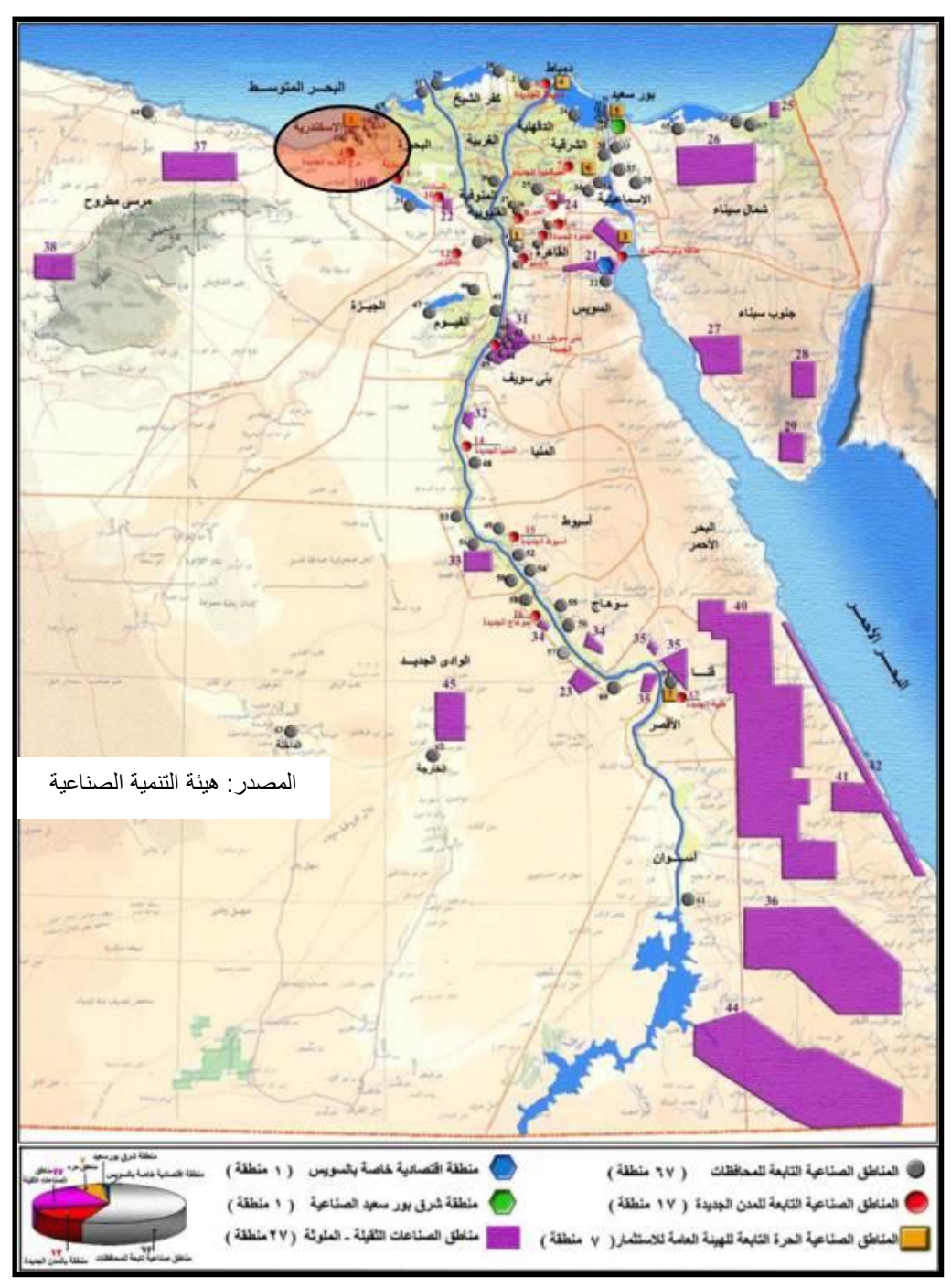

شكل ( ) المناطق الصناعية بمصر وتبعياتها
المناطق الصناعية بمصر:

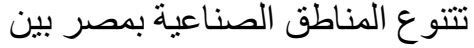

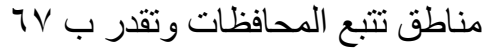
منطقة ومناطق تقع بال مدن الجديدة وتمثل

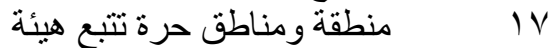
الاستثمار ومناطق خاصة ويوضة حئح الثنكل

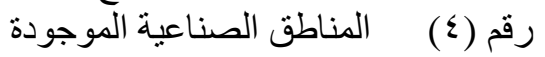

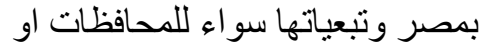

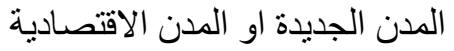

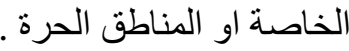

الملامح العامة لإستراتيجية التنمية

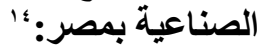
ان تكـون التنميـة الصناعيـة هـي قاطـرة

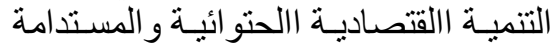

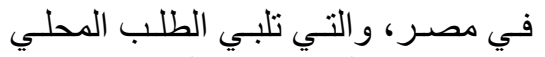

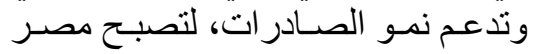

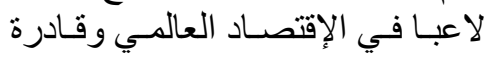

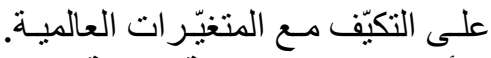
الأهداف الإسترا تيجية للتنمية الصناعية التية • بمر: زيادة معدل النمو الصناعي ليصل

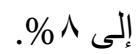

زيادة نسبة مساهمة الناتج الصناعي

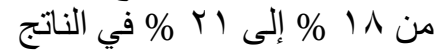
المحلي. زيـادة مسـاهمة القطـاع الخـاص المغرة

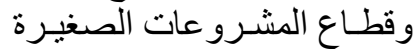

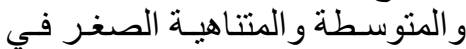
الناتج المحلي الإجمالـي. زيادة معدل نمو الصادر ات ليكون الإني

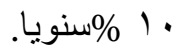
توفير r مليون فرصة عمل الئقة ومنتجة. تحسين الأداء المؤسسي. 
التعريف بمحافظة الاسكندرية:

هى احدى المحافظات الثلاث المكونة لاقليم الاسكندرية بجانب محافظتى البحيرة ومطروح وتطل على ولى البحر المتوسط

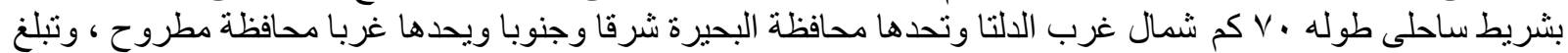

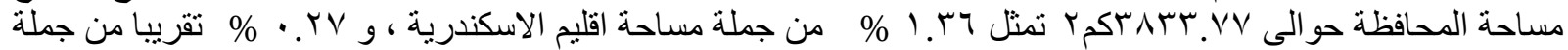

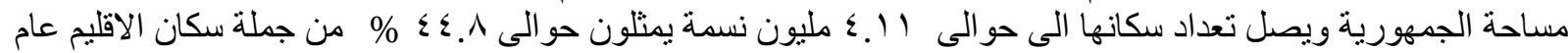

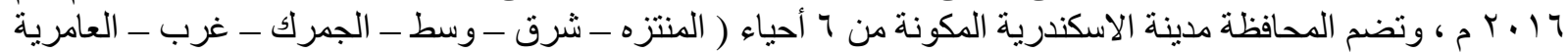

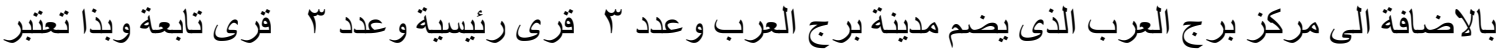

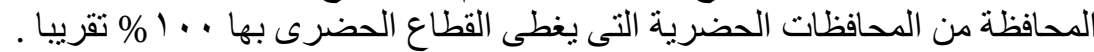
ويتضح ان محافظة الاسكندرية تضم (• ( مناطق) تبلغ مساحتهم حو الي بr ب ألف فدان كما هو موضح بالجدول رقم (1)

مابين مناطق حرة ومايتبع المحافظة.

\begin{tabular}{|c|c|c|c|}
\hline \multicolumn{4}{|c|}{ جدول ( ) يبين المناطق الصناعية بمحافظة الاسكندرية وتبعياتها ومسـاحتها } \\
\hline النسبة \% & المساحة فدان & التبعية الصناعية & اسم المنطقة \\
\hline. $\mathrm{VV}$ & 1 Ч人... & محافظات & المنطقة الصناعية بالناصرية \\
\hline IT.YV & rovi... & محافظات & المنطقة الصناعية بر غم قبلي وبحري \\
\hline r.Vt & $\wedge \backslash \leqslant .$. & محافظات & لمنطقة الصناعية كيلو اب الطريق الصحر اوي \\
\hline. $\mathrm{VT}$ & $17 . .$. & محافظات & لمنطقة الصناعية سبيكو \\
\hline.+1 & r... & محافظات & لمنطقة الصناعية العجمي قبلي بيطاش \\
\hline YI. II & $\sum 711 . .$. & محافظات & منطقة النهضتة الصناعية وتوسعاتها \\
\hline IT.0 & r^o1... & محافظات & لمنطقة الصناعية بام زغبو \\
\hline 7.41 & Irov.1E & مناطق حره & المنطقة الحرة العامة بالاسكندرية \\
\hline ro. r & $0 \leq 70 . .$. & مدن جديدة & برج العرب الجديده \\
\hline 15.99 & 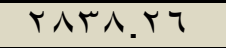 & مطورين & منطقة المطورين ( بمدينة برج العرب \\
\hline $1 \cdots$ & 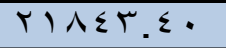 & & الإجمالي \\
\hline
\end{tabular}

الأنثطة الصناعية فى محافظة الاسكندرية:

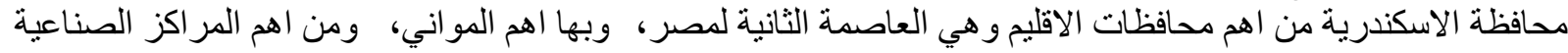

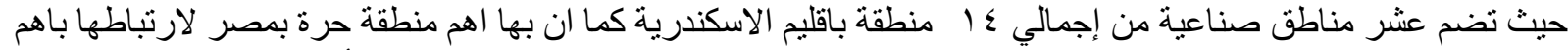

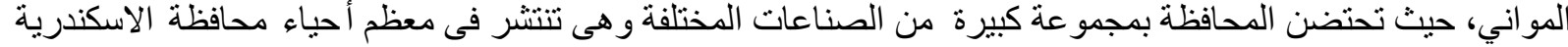

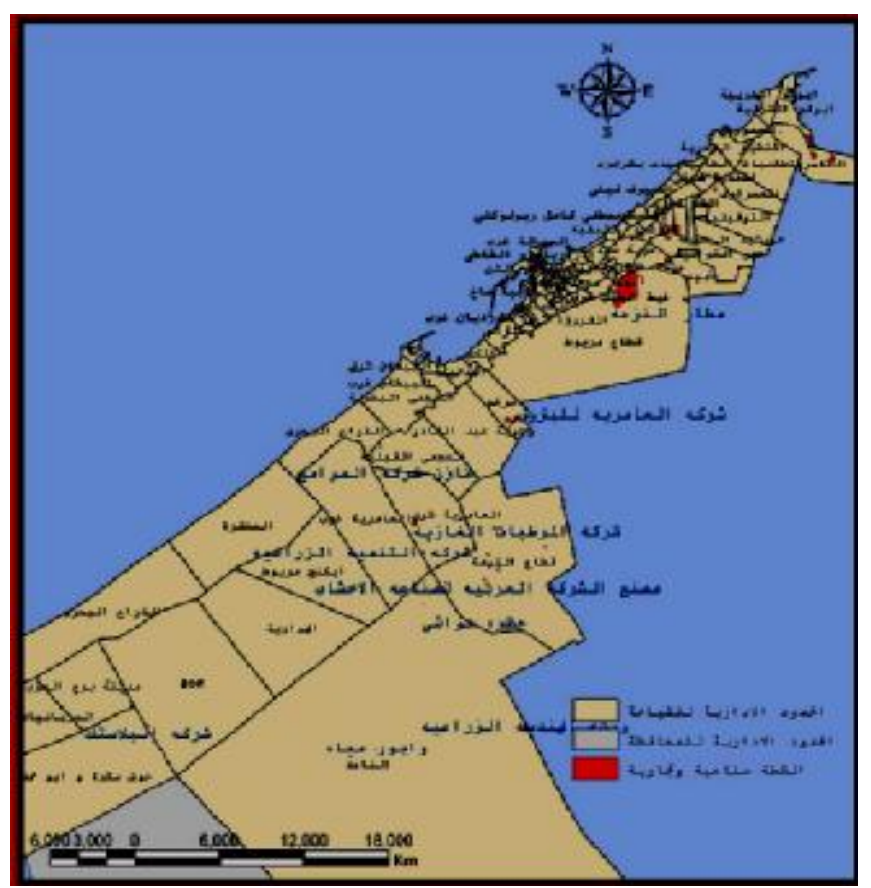

شكل (0) المناطق الصناعية بمحافظة

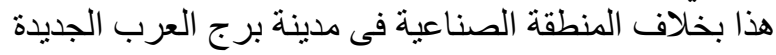

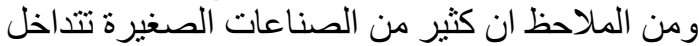

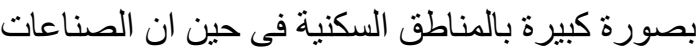

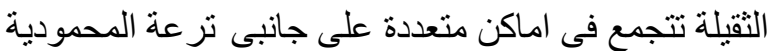

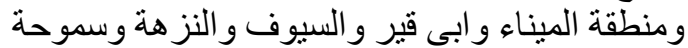
و الدخيلة و المكس و العامرية ؛ فالصناعات فير الغذائية و التعليب

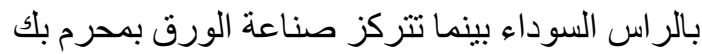

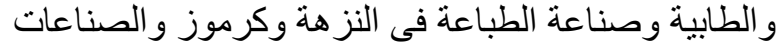

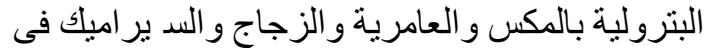

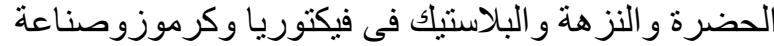

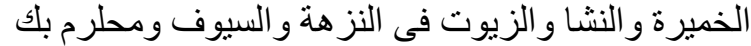

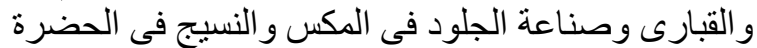

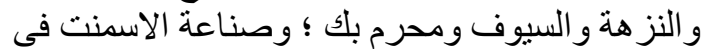
بالمكس و الصناعت المعدنية فى النز هة و الظاهرية و والدخيلة

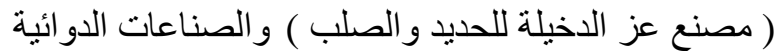

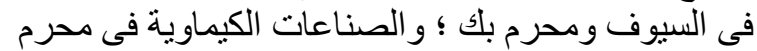

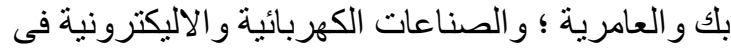

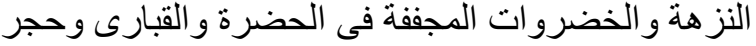
النواتية ؛ و الغاز ات الصناعية فى الحضرة وات الدخيلة ؛ 


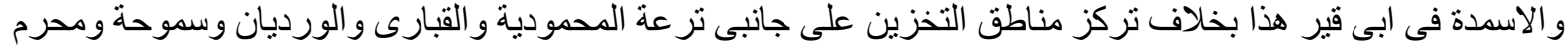

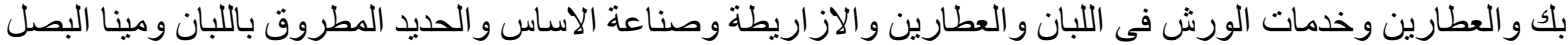

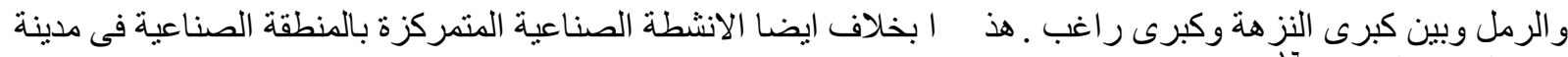
برج العرب الجديدة.

المنشأت الصناعية بمحافظة لإسكندرية:

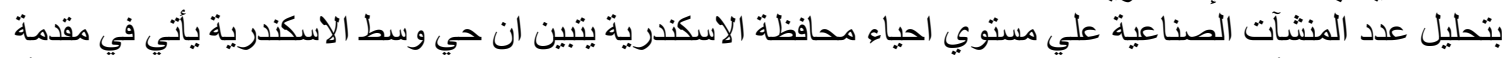

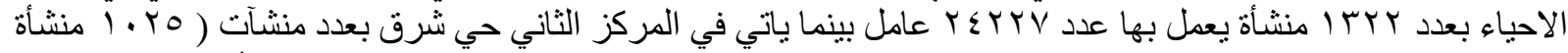

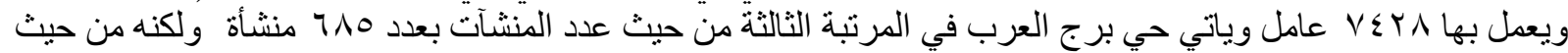

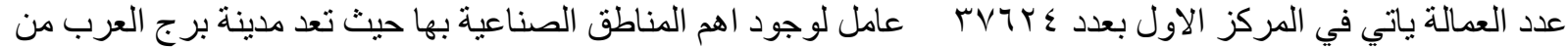

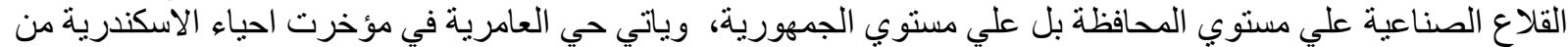

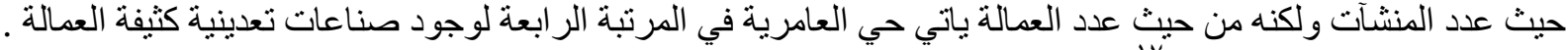

كما هو مبين في جدول رقم (r)

جدول رقم (ץ) بيان الصناعات القائمة بالمحافظة وعدد المنشأت والعمالة

\begin{tabular}{|c|c|c|c|c|c|c|c|c|c|c|c|c|c|c|c|c|c|c|c|}
\hline \multicolumn{2}{|c|}{ الإبملي } & \multicolumn{2}{|c|}{ صناعات تحريلية. } & \multicolumn{2}{|c|}{ هوران غأنانة } & \multicolumn{2}{|c|}{ الوقرق والطبائة } & \multicolumn{2}{|c|}{ غزل ونسبج } & \multicolumn{2}{|c|}{ ذثب ومنتجاته } & \multicolumn{2}{|c|}{ متتجلت هلنسبة } & \multicolumn{2}{|c|}{ متتجلت مدلنية اسياسيداي } & \multicolumn{2}{|c|}{ ذلدات تلعبئة| } & \multicolumn{2}{|c|}{ كبمايات } \\
\hline علد العلة & | لسنئن & |لعلالة & |لنثئن & |لعلالة & | لنشئن & |علدة & |لهنثئ & |علدلة & | علدئن & | علدلة & | علدئن & |علة & |لدئن & | عدد الع & | & ب| لععالة & ع & & \\
\hline IFTis. & ؛ov. & r:s9. & 10.11 & 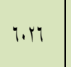 & ؛ & rirs & wr & 9911 & $\pi$ & likA & wr & 0.11 & ryr & דיד & r.v & rra19 & 41 & $m ? \div$ & $11 \mathrm{~K}$ \\
\hline
\end{tabular}

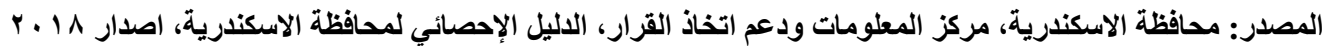

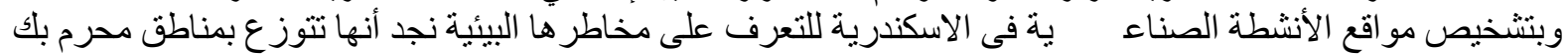

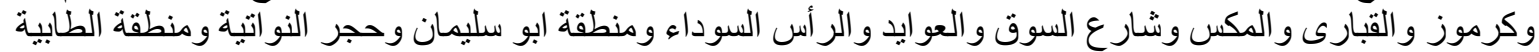

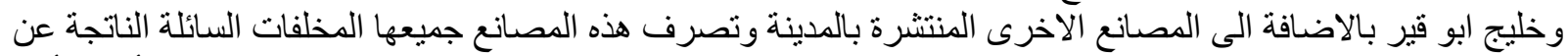

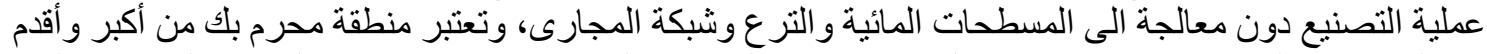

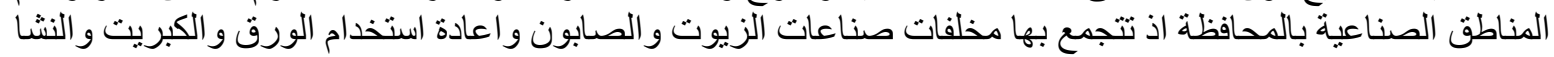

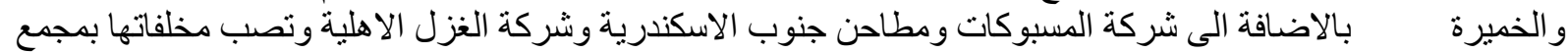

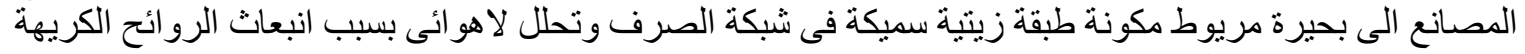

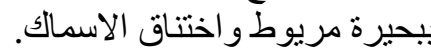

المخاطر البيئية للانشطة الصناعية على محيطها العمر التئي:

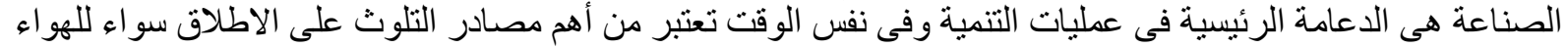

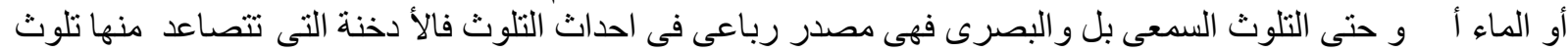

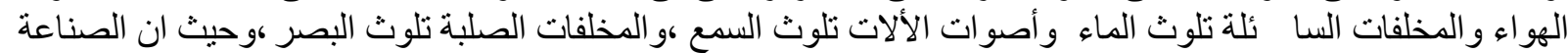

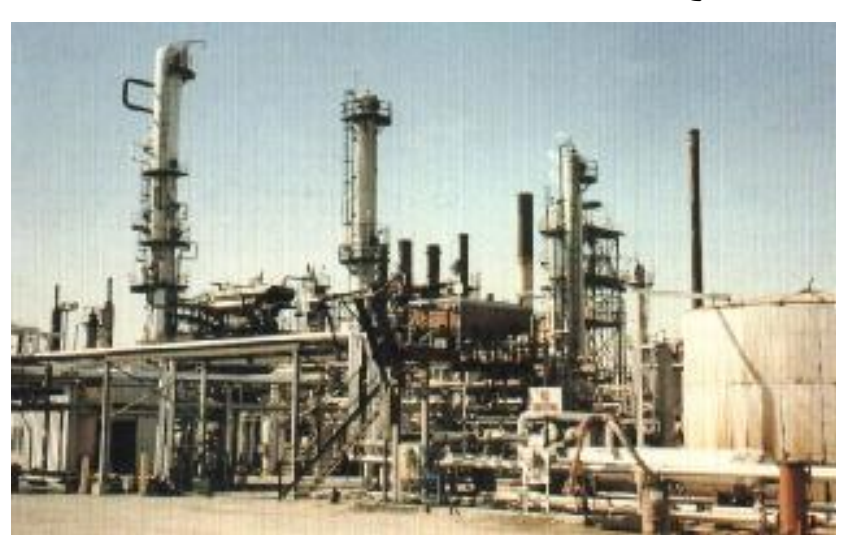

شكل رقم (7) مصانع البترول بمنطقة الاخيلة

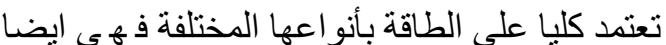

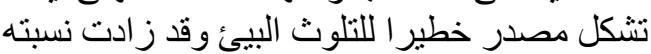

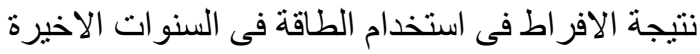

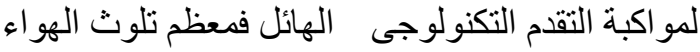

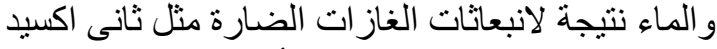

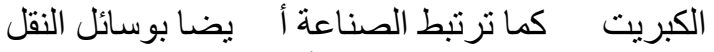

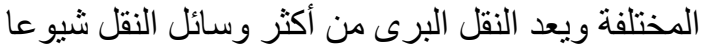

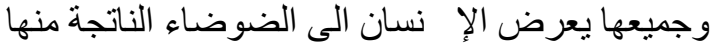

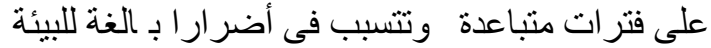

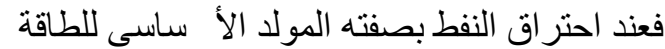

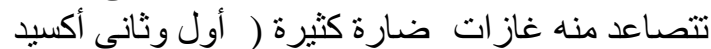

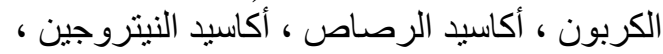

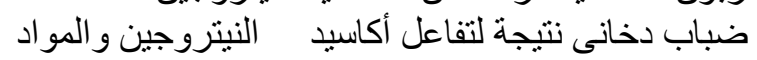


الهيدروكربونية ، ألجسيمات و المركبات الكيميائية ) علاوة على الأمر اض التى تسبيها للانسان من التهابات العين و الأنف

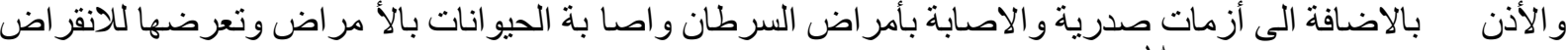

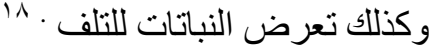
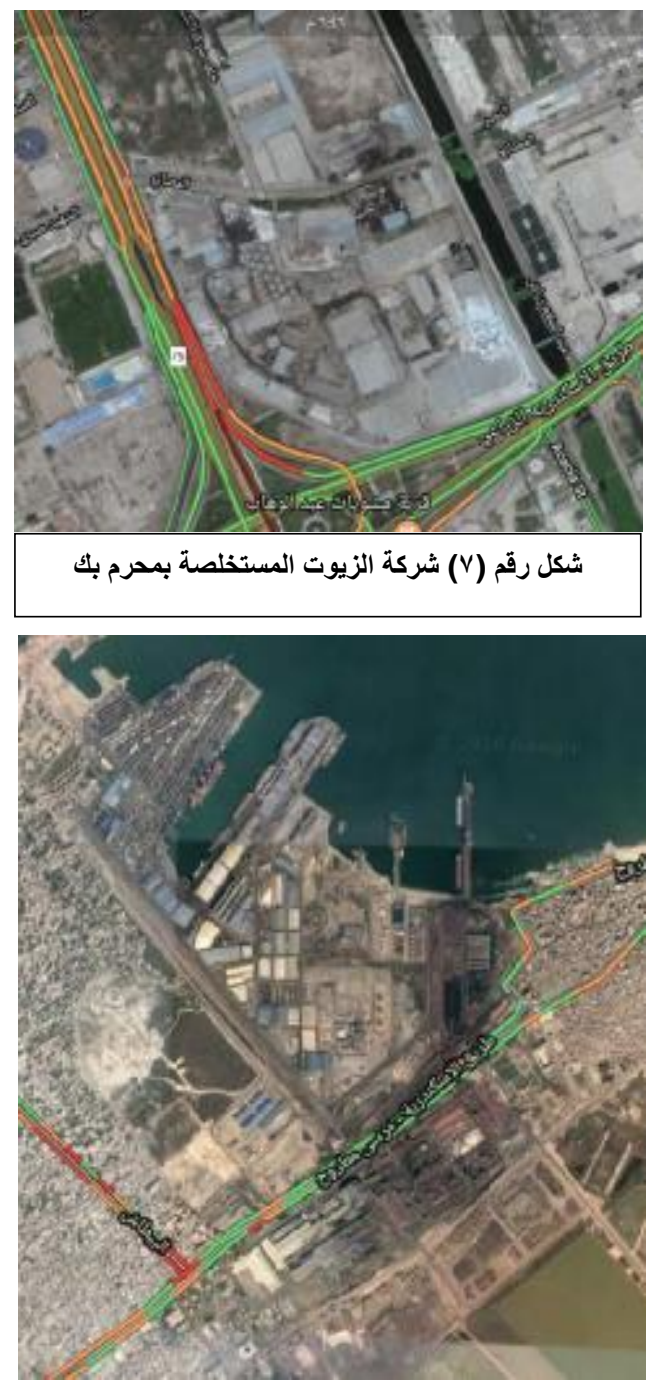

شكل رقم (^) مصنع عز الاخيلة للديد والصلب

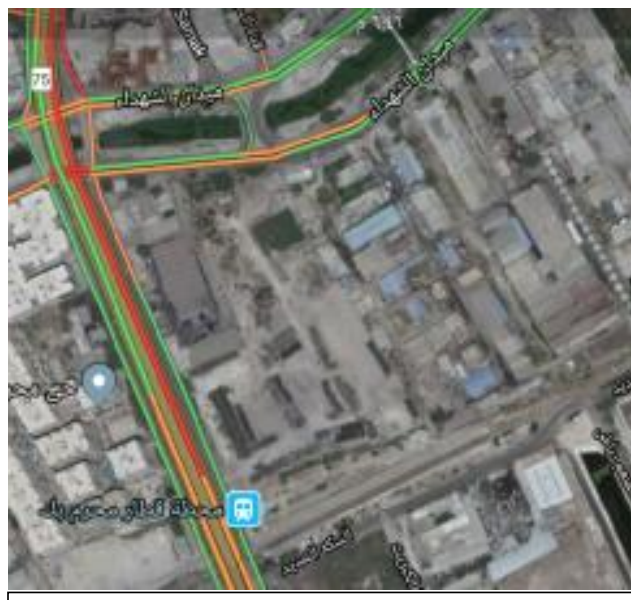

شكل رقم (9) شركة تصنيع السجائر بمحرم بك
أهم بؤز التلوث الصناعي بمدينة الاسكندرية:

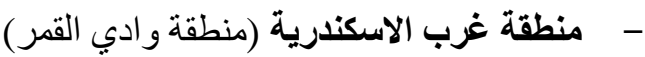

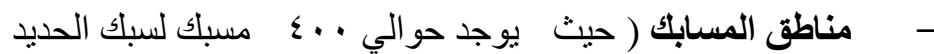

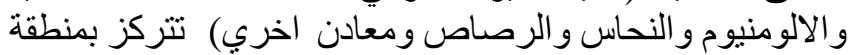

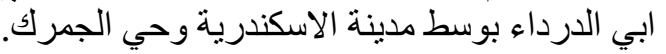
- - منطقة البتروكيماويات التي تتركز بالعامرية.

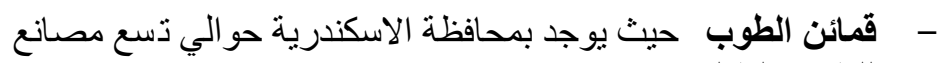
للطوب الطفلي.

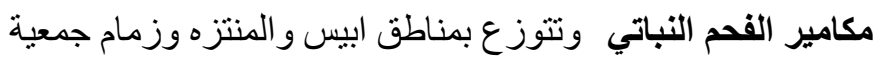

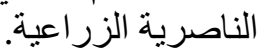
- ورش الرخام حيث يوجد حور الي 10 بحي وسط. تلوث بحيرة مريوط : تعرضت بحيرة مريوط خلال الثلاثثن عاما

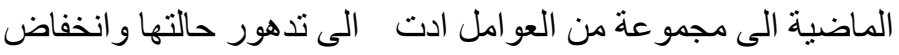

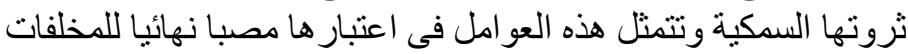

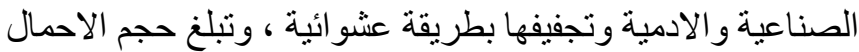

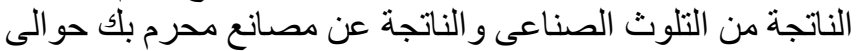

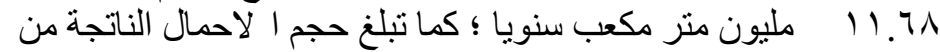

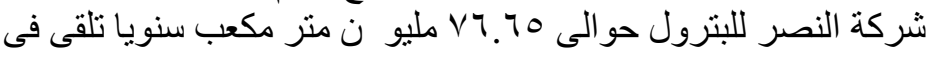

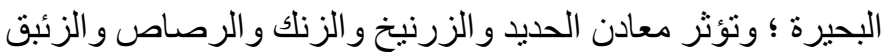

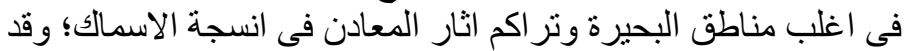

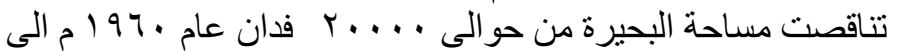

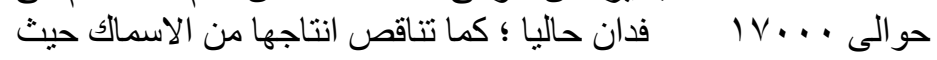

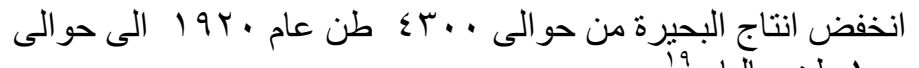

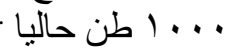

تأثير الأنثطة الصناعية على النقل والمرور فى محيطها العمر انى:

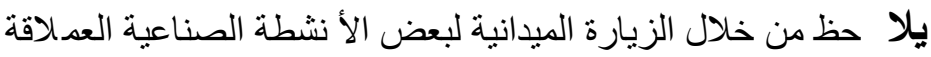

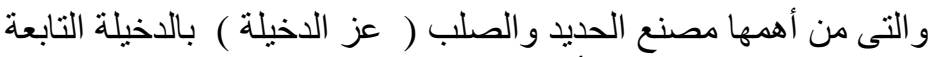

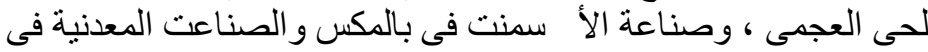

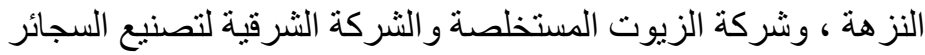

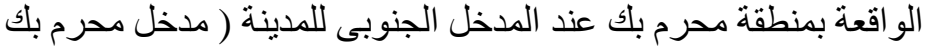

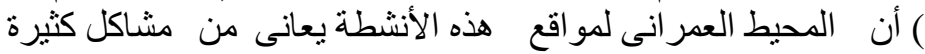

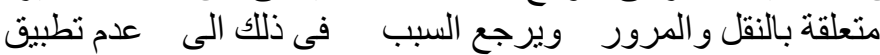

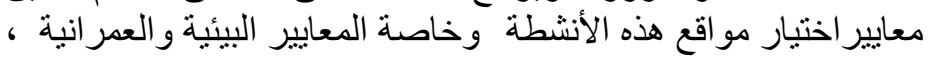

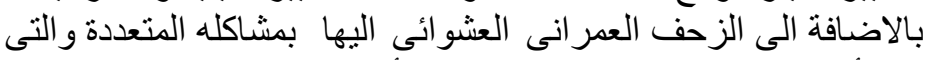

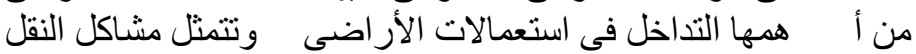

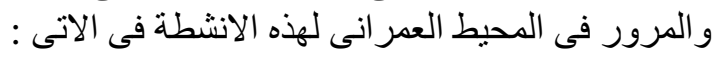

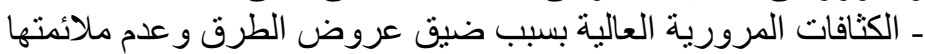
لأحجام المرور حيث ان جميع المناطق المحيطة بالأنشطة الصناعية الصنية هى مناطق عمر انية عشو ائية غير مخططة. ـ الزيادة فى اعداد سيار ات النقل الكبيرة الداخلة والخارجة من مواقع

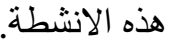
- عدم وجود مساحات خالية حول مو اقع هذه الأنشطة لاستخدامها 
كساحات انتظار للسيار ات المستخدمة فى الثحن و التفريغ. ـ الضوضاء الناتج عن الزحام المروري حول هذه الأنشطة حيث يمثل ال لضوضاء عاملا هاما وخطير ا يتعارض مع راحة الانسان.

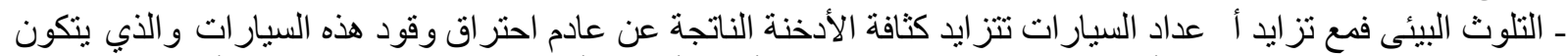

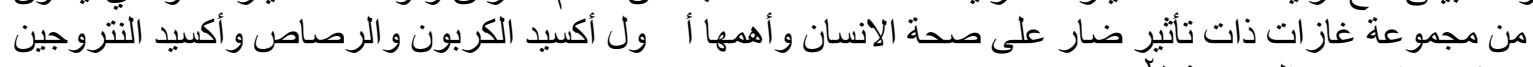

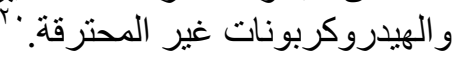

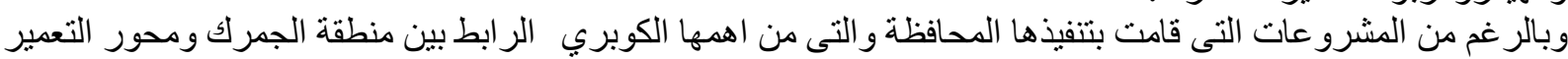
بغية لحل هذه المشاكل الا ان الامر ماز ال معقدا وما هذه المشرو عات التات الا بمثابة حلول مؤقتـة.

الإستراتيجيات والسياسات المقترحة:

أولا: الإستراتيجيات المتبعة فى الدول الصناعية الكبرى من أجل استدامة حضرية للمدن:

ا ـ إستر اتيجية إعادة التطوير و الحفاظ و التأهيل للمناطق الصناعية:

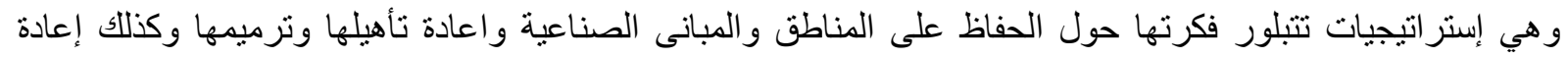

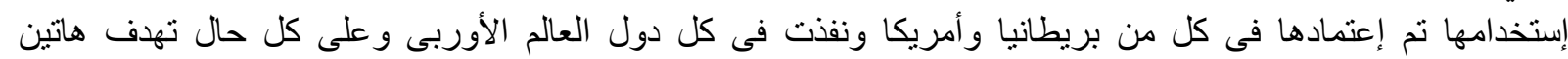
الإستر اتيجيتين إلى الإستدامة و الحفاظ على البئي البئة الطبيعية.

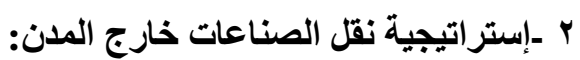

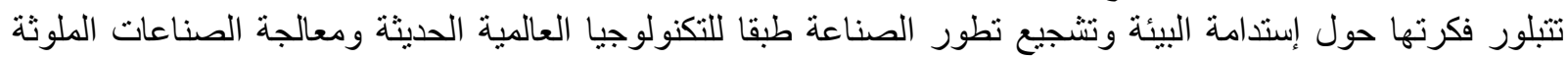
وتثجيع التتمية المستدامة والطاقات المتجددة إقتصاديا وحفاظا على المناطق التى تنقل إليها الصناعة من مخاطر التلوث التهات الصناعى.

r ـ إستراتيجية الأحزمة والأنطقة الخضر اءع لمدينة صناعية مستدامة:

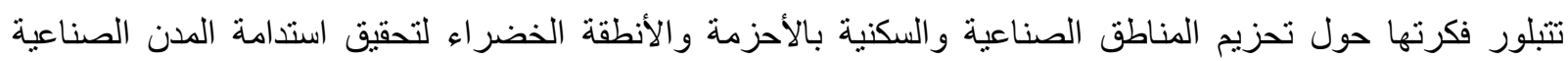

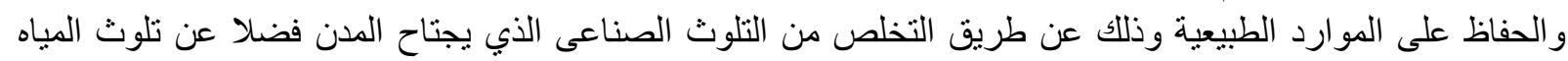

بمصادره المختلفة.

؛ - إستراتيجية التكامل بين شبكة الطرق واستعمالات الأراضى فى المناطق الصناعية:

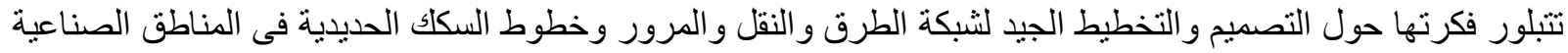

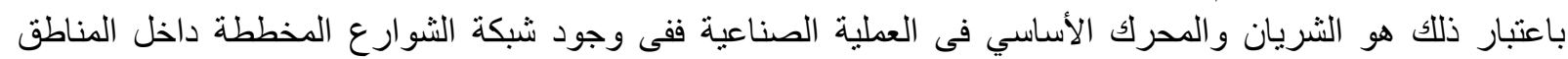

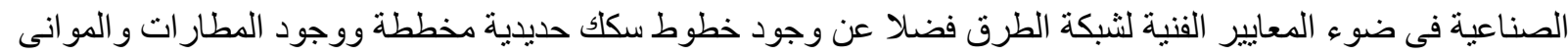
دلالة على ديناميكية الحركة المستمرة بدون زحام مروري مما يساعد على تحقيق الإستدامة فى المناطق الصناعية.

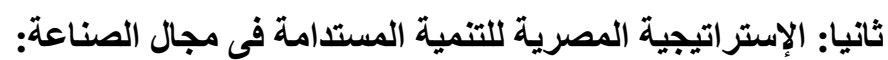

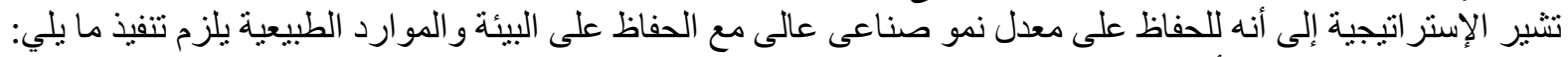

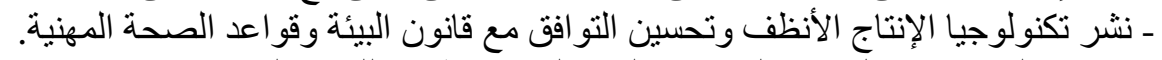

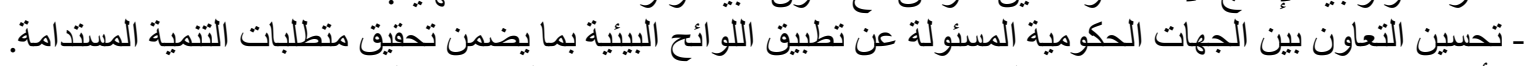

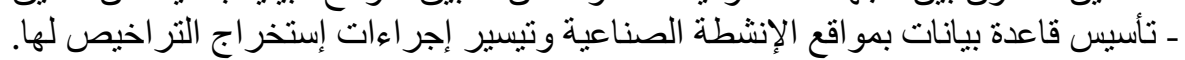

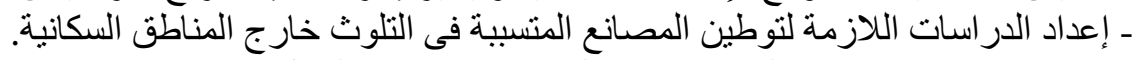
وتتعرض هذه الاستر اتيجية لمجمو عة من التحديات يوضحهات التها الثكل رقم (• (1) 


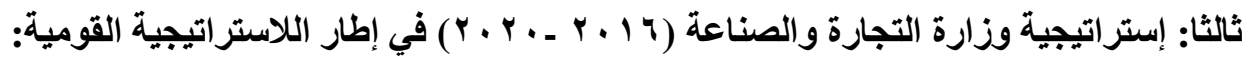

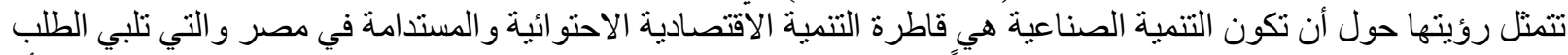

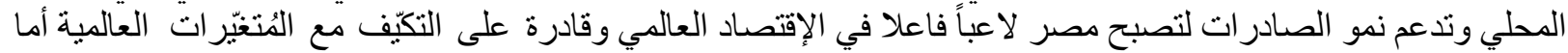

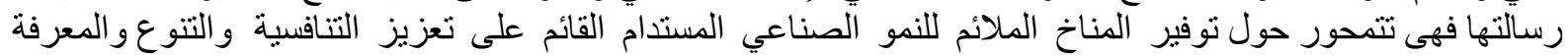

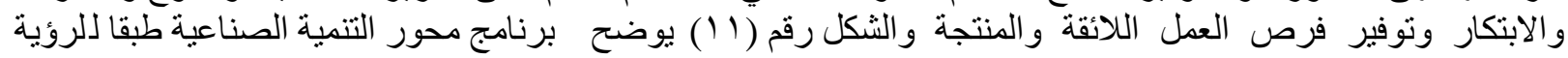
الاستر اتيجية.

وقد اقترحت الإستر اتيجية تطوير العديد من المشرو عات الصناعية على مستوى المحافظات فمنها فى محافظة الاسكندرية

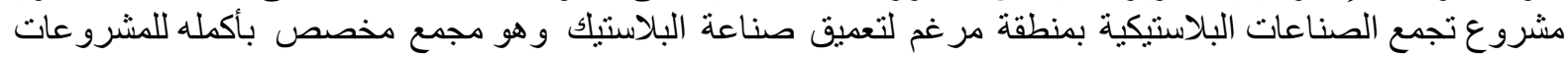
الصغيرة و المنتوسطة بالإضافة إلى تجمعات الصناعات التكنولوجية.

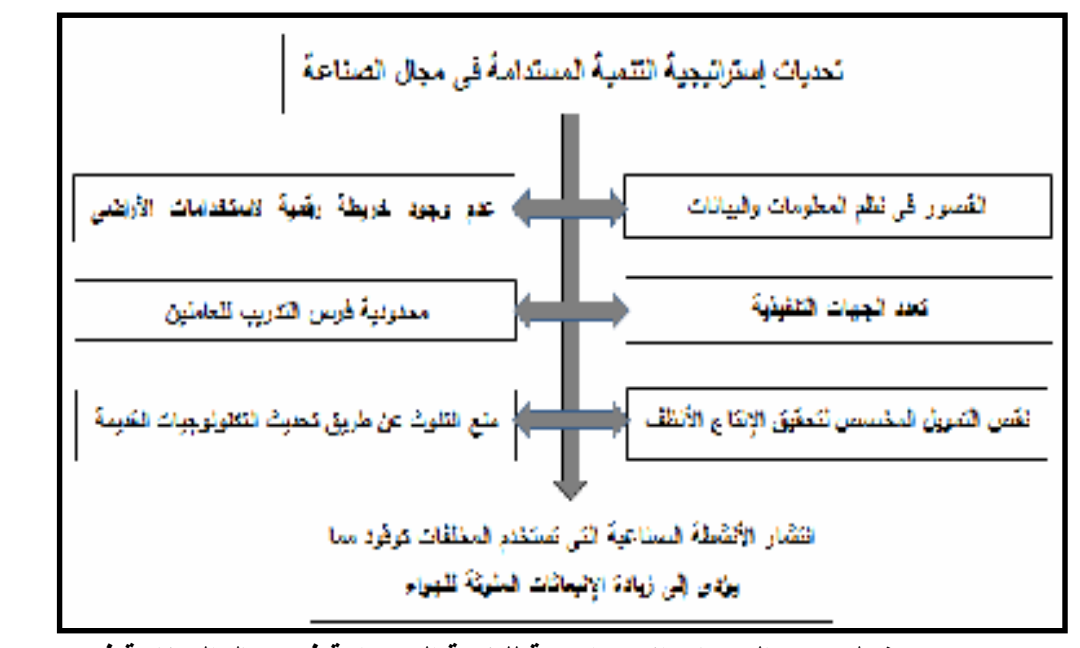

شكل · 1 • التحديات الاستراتيجية للتنمية المستدامة فى مجال الصناعة فى مصر .

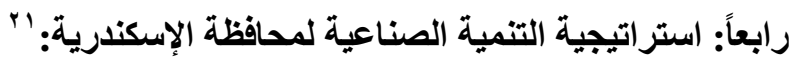

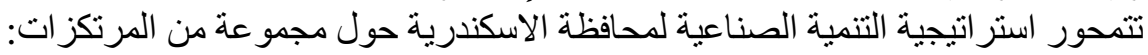

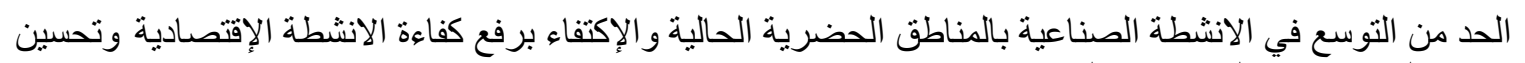
مستوي الخدمات ومعالجة الاثار البيئية. وضع خطة متكاملة للحد من الإستخدام العشو ائى لأر اضيى المحافظة مع تطوير المناطق العشوائية الحالية و امدادها بالمر افق و الخدمات العامة.

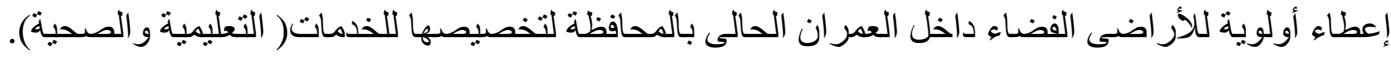

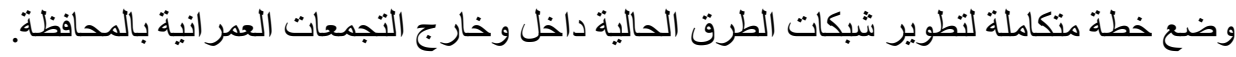

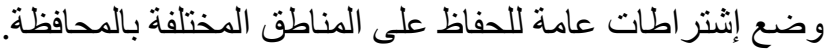

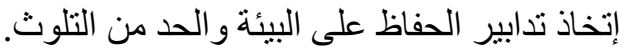

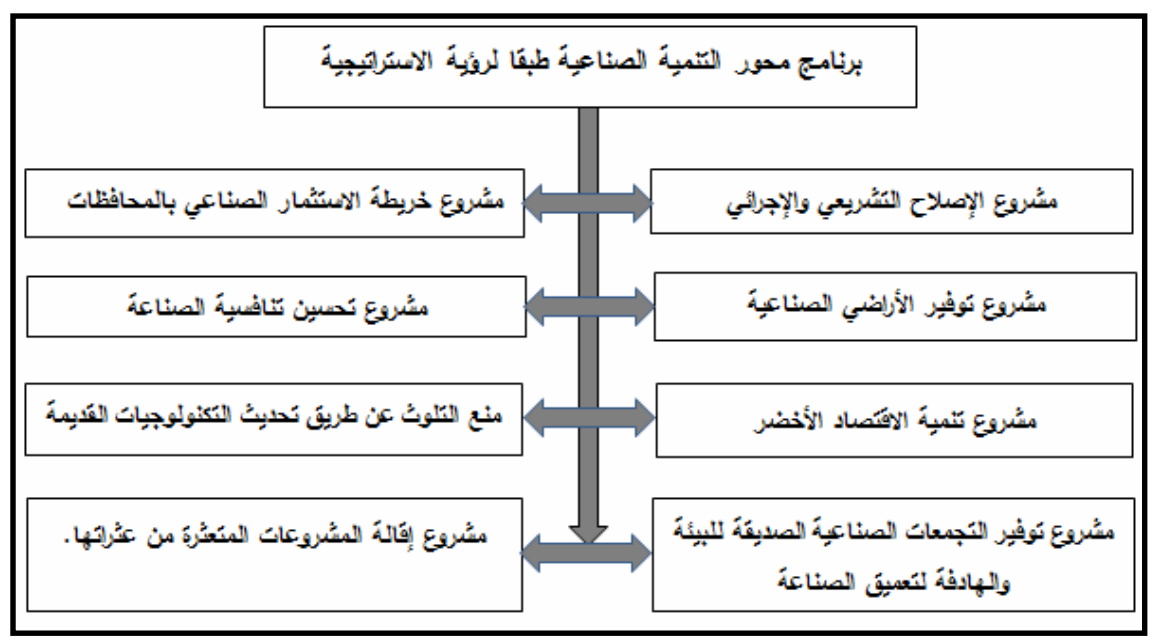

شكل ل1 إلروية الاستراتيجية لمحور التنمية الصناعية فى مصر . 
ـ وضع أليات لتحقيق الصناعة الخضئ التراء كأحد الخيار ات الأساسية المتاحة لتعديل مسار التتمية الصناعية وتعزيز استدامتها

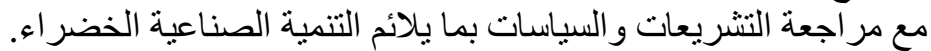

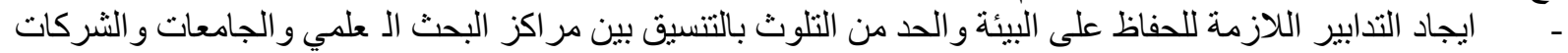

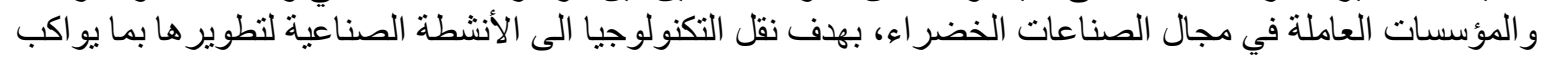

التطور دات العصرية الحديثة.

ـ تفعيل دور الأجهزة الرقابية المعنية برصد الفئة المخالفات الصناعية وحماية البيئة.

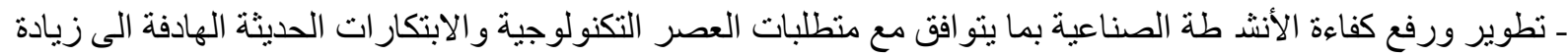

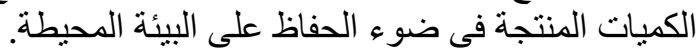
ـ التوجه نحو المتنز هات الصناعية الإيكولوجية يؤكد على تحقيق الإستدامة الصناعية وتقليل معدلات التلوث البيئى.

ـ التوصيات على المستوي الإقليمي:

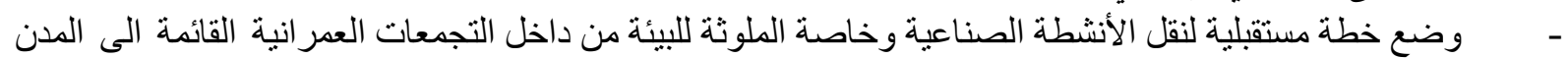

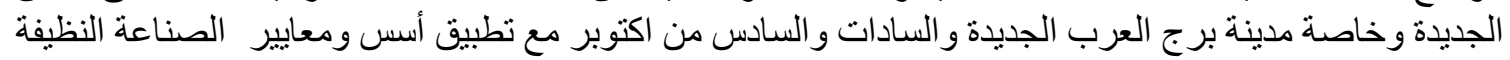

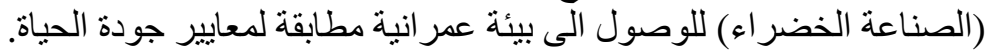

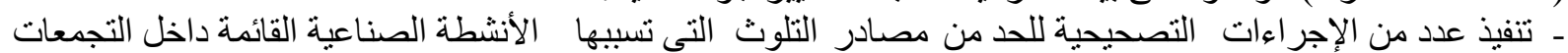

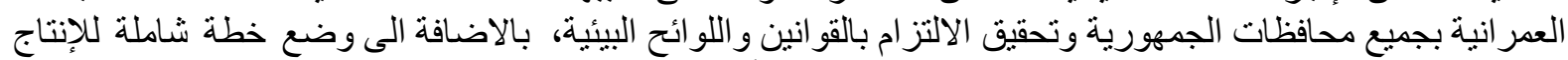

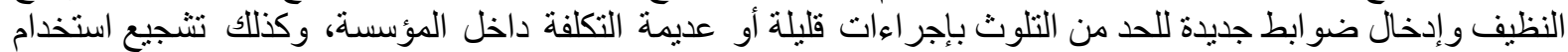

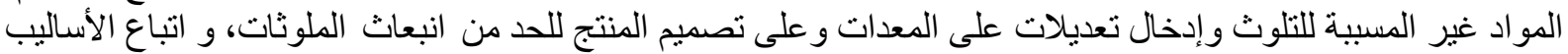

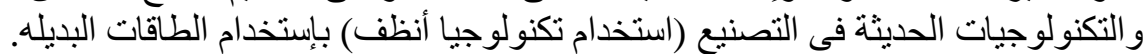

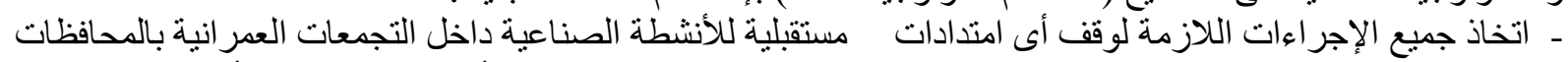

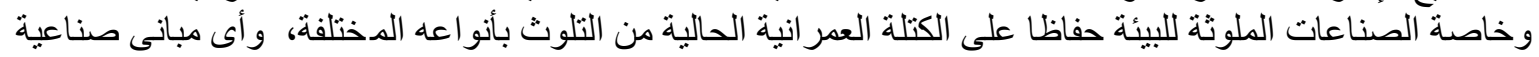

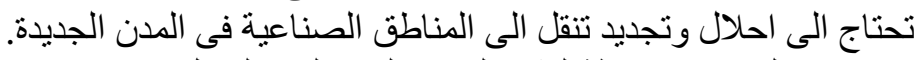

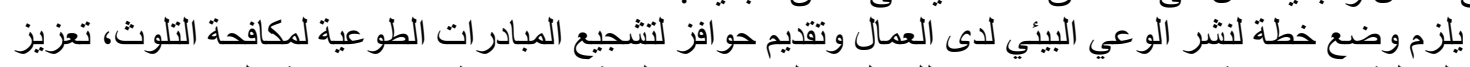

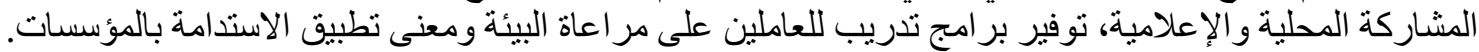

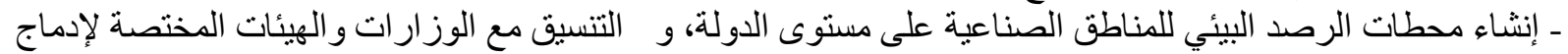

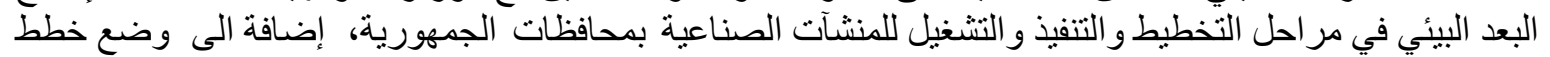

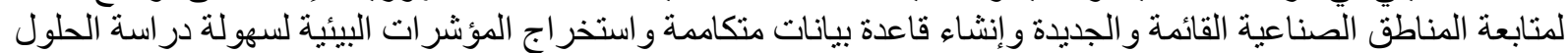

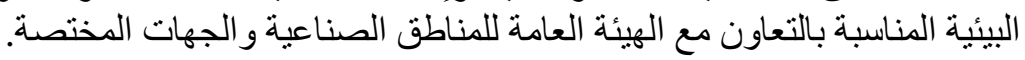

التوصيات الخاصة بمحافظة الإم سكندرية:

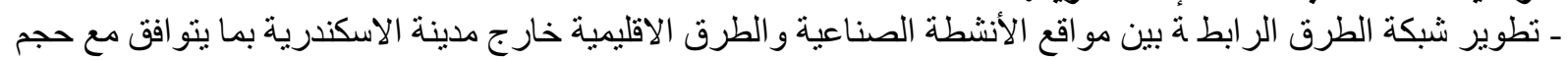
المرور المنولد عن هذه الانشطة.

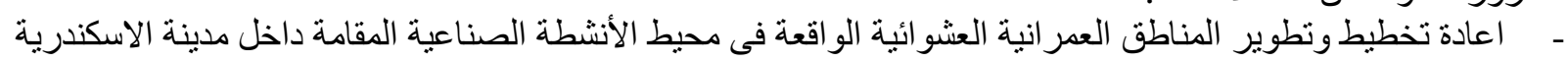

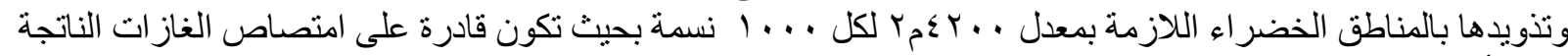
عن الأنشطة الصناعية.

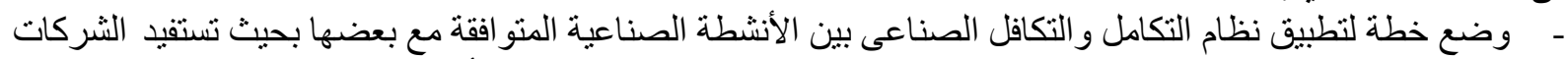

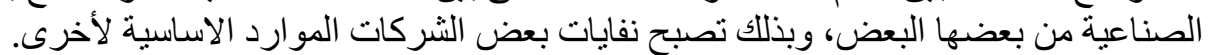

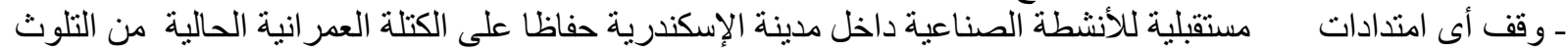

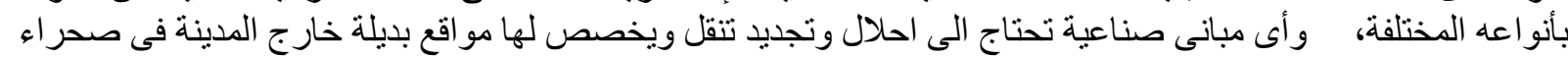
المحافظة.

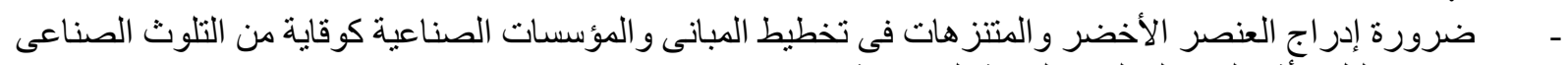
وبنسب تحقق تقليل الأثر البيئى لعمليات التنمية الصناعية.

ـ التوصيات على المستوي المناطق الصناعية:

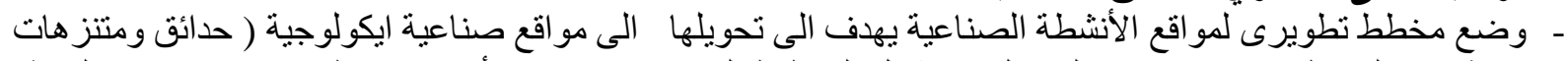

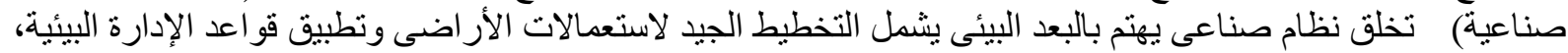

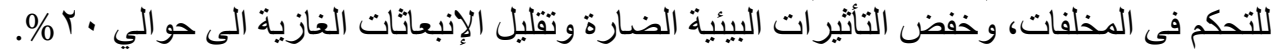




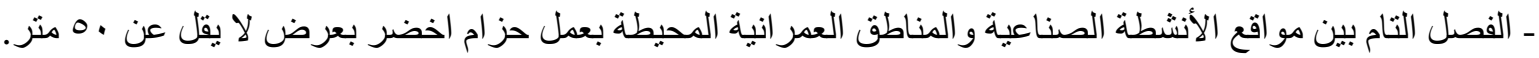

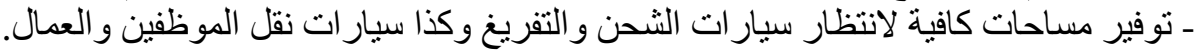

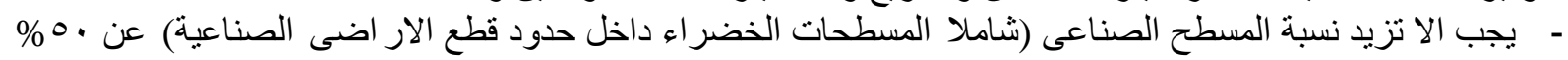
من اجمالى مسطح المنطقة الصناعية.

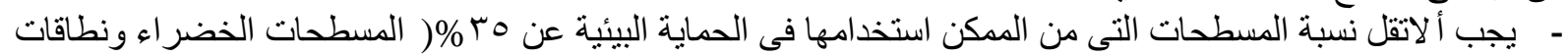
الحماية) من اجمالى مسطح الآنطية المطنة الصنات الصناعية.

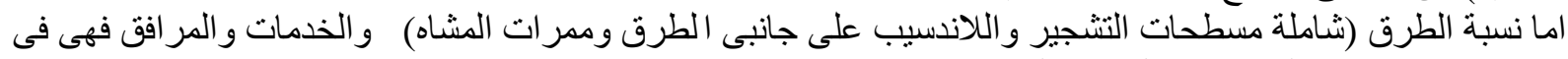

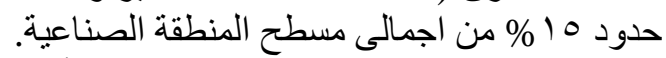

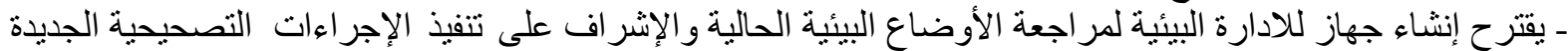
للحد من مصادر التلوث في الوحدات الإنتاجية وتحقيق الالتزام بالقو انين و اللو ائح البيئية، وتنفيذ الإجر اءات الإتية الوقائية.

ـ توصيات للتحول من الصناعات الملوثة للبيئة الي الصناعات المتوافقة مع البيئة:

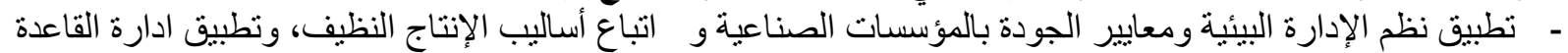

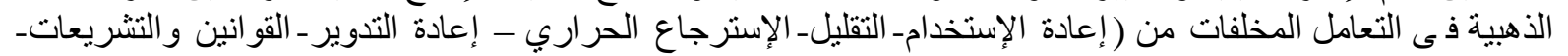
الإبتكار -إعادة التفكير) (

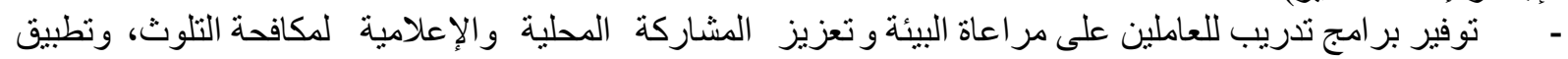

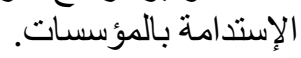

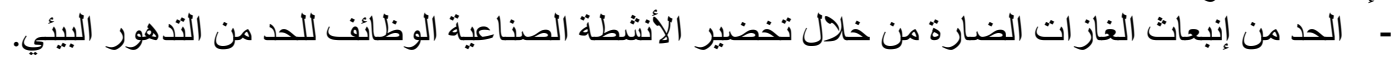

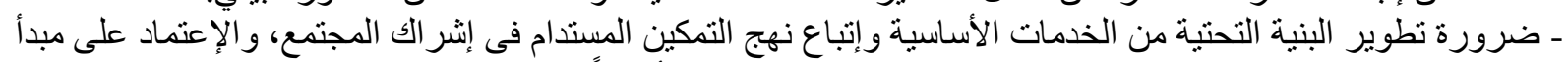

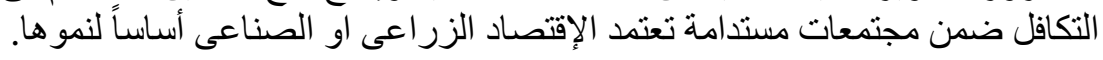

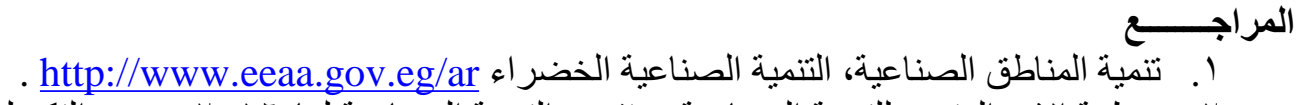

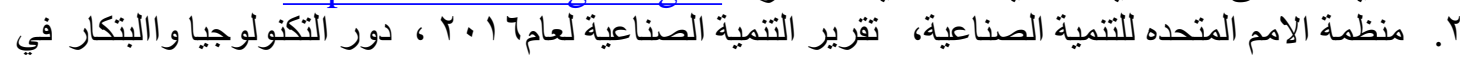

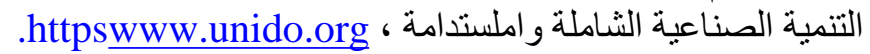
r. الثال، مها مصطفي، دور الابتكار في فئة التنمية الصناعية المستدامة في مصر، معهد التخطيط القومي،

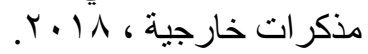

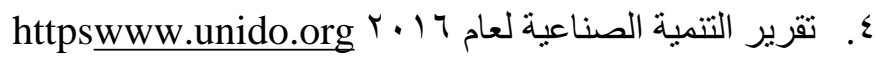

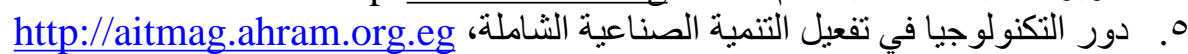

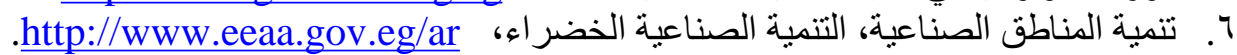
V. . محمود، نور هان عبدالرحمن، الصناعة الخضر اءة وأثرهاء هاء على التنمية المستدامة، المركز الديمقر اطي العربي

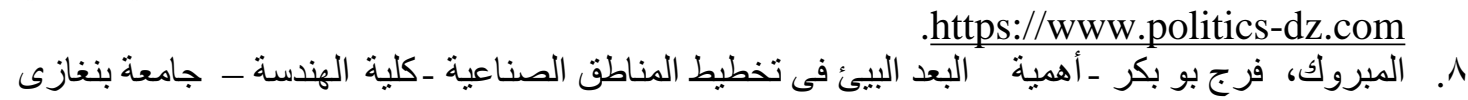
faraj.elmabrouk@uob.edu.ly.

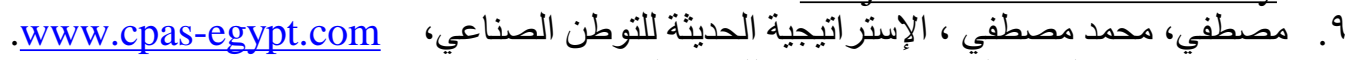

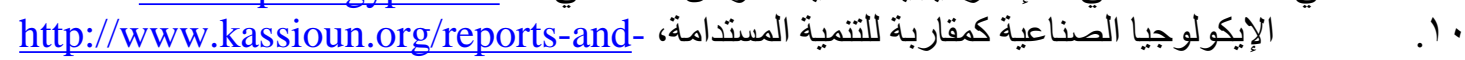
pinions/item

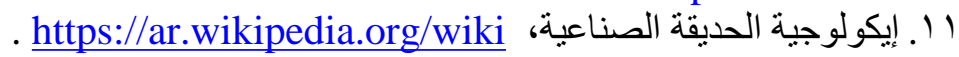

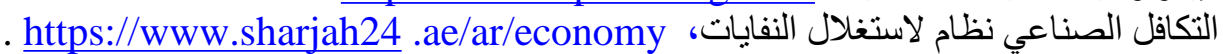

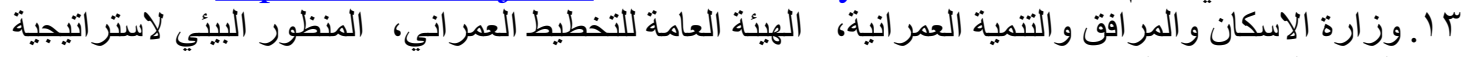

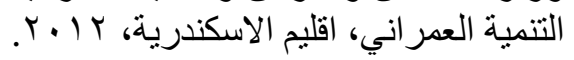

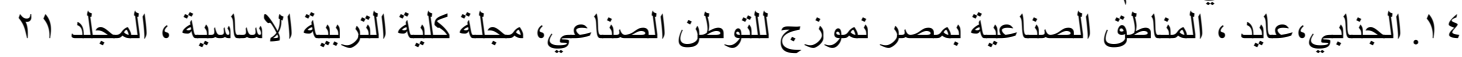

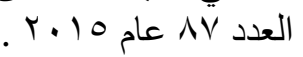

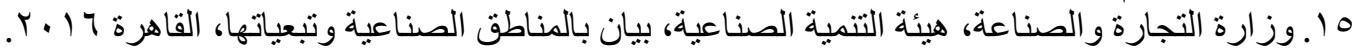

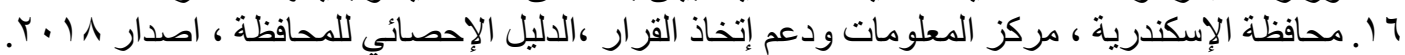

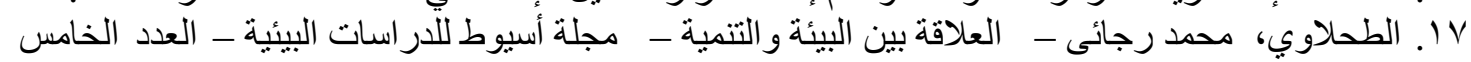

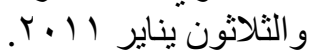
1 ا التوصيف البيئي لمحافظة الاسكندرية - وز ارة الدولة لنشئونالبيئة - • • ب. 
9 1 . عزب، محمد عبدالفتاح، تحديث المخطط العام لمدينة الاسكندرية لعام هץ • ب ، رسالة ماجستير كلية الهندسة

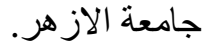
• †. عفيفي، احمد كمال،ؤؤاد، حسن - تخطيط الطرق و النقل و المرو ر في المدينة ، دار الحكيم للطباعة و النشر

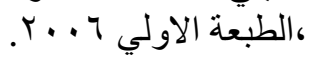

ا ب. وز وارة الاسكان و المر افق و التتمية العمر انية، الهيئة العامة للتخطيط العمر اني، استر اتيجية التنمية العمر اني

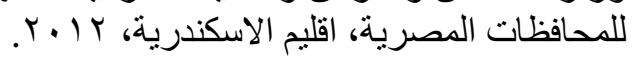

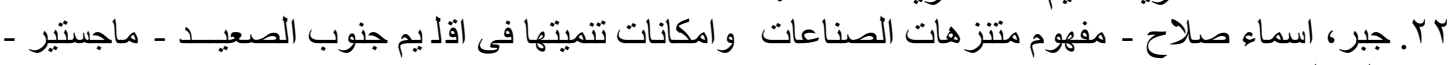

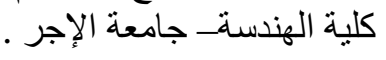

